\title{
Harmonin-b, an actin-binding scaffold protein, is involved in the adaptation of mechanoelectrical transduction by sensory hair cells
}

\author{
Nicolas Michalski • Vincent Michel • Elisa Caberlotto • Gaelle M. Lefèvre • \\ Alexander F. J. van Aken • Jean-Yves Tinevez • Emilie Bizard • Christophe Houbron • \\ Dominique Weil • Jean-Pierre Hardelin • Guy P. Richardson • Corné J. Kros • \\ Pascal Martin • Christine Petit
}

Received: 11 March 2009/Revised: 25 July 2009 / Accepted: 29 July 2009 /Published online: 11 September 2009

(C) The Author(s) 2009. This article is published with open access at Springerlink.com

\begin{abstract}
We assessed the involvement of harmonin-b, a submembranous protein containing PDZ domains, in the mechanoelectrical transduction machinery of inner ear hair cells. Harmonin-b is located in the region of the upper insertion point of the tip link that joins adjacent stereocilia from different rows and that is believed to gate transducer
\end{abstract}

Vincent Michel, Elisa Caberlotto and Gaelle M. Lefèvre contributed equally to the work.

Pascal Martin and Christine Petit contributed equally to the work.

Electronic supplementary material The online version of this article (doi:10.1007/s00424-009-0711-x) contains supplementary material, which is available to authorized users.

N. Michalski $\cdot$ V. Michel $\cdot$ E. Caberlotto $\cdot$ G. M. Lefèvre $\cdot$

E. Bizard $\cdot$ D. Weil $\cdot$ J.-P. Hardelin $\cdot$ C. Petit $(\square)$

Institut Pasteur, Unité de Génétique et Physiologie de l'Audition,

Paris 75015, France

e-mail: christine.petit@pasteur.fr

N. Michalski $\cdot$ V. Michel $\cdot$ E. Caberlotto $\cdot$ G. M. Lefèvre $\cdot$

E. Bizard $\cdot$ D. Weil · J.-P. Hardelin $\cdot$ C. Petit

Inserm UMRS 587,

Paris 75015, France

N. Michalski $\cdot$ V. Michel $\cdot$ E. Caberlotto $\cdot$ G. M. Lefèvre $\cdot$

J.-Y. Tinevez • E. Bizard - D. Weil · J.-P. Hardelin • P. Martin •

C. Petit

Université Pierre et Marie Curie,

Paris 75015, France

J.-Y. Tinevez $\cdot$ P. Martin

Laboratoire Physico-Chimie Curie, Institut Curie,

26 rue d'Ulm,

Paris 75005 , France

J.-Y. Tinevez $\cdot$ P. Martin

CNRS UMR 168 ,

Paris 75005, France channel(s) located in the region of the tip link's lower insertion point. In $U s h 1 c^{\mathrm{dfcr}-2 \mathrm{~J} / \mathrm{dfcr}-2 \mathrm{~J}}$ mutant mice defective for harmonin-b, step deflections of the hair bundle evoked transduction currents with altered speed and extent of adaptation. In utricular hair cells, hair bundle morphology and maximal transduction currents were similar to those

\section{Collège de France,}

C. Petit

Paris 75015, France

A. F. J. van Aken · G. P. Richardson • C. J. Kros

School of Life Sciences, University of Sussex,

Falmer, Brighton BN1 9QG, UK

\section{Houbron}

Recombinaison Homologue-Institut Cochin,

Université Paris-Descartes,

Inserm U567, CNRS UMR8104,

24 rue du faubourg Saint Jacques,

Paris 75014, France

\section{J.-Y. Tinevez}

Imagopole, Institut Pasteur,

Paris 75015, France

Present Address:

G. M. Lefèvre

NIDDK, NIH,

Bethesda, MD 20892-0540, USA 
observed in wild-type mice, but adaptation was faster and more complete. Cochlear outer hair cells displayed reduced maximal transduction currents, which may be the consequence of moderate structural anomalies of their hair bundles. Their adaptation was slower and displayed a variable extent. The latter was positively correlated with the magnitude of the maximal transduction current, but the cells that showed the largest currents could be either hyperadaptive or hypoadaptive. To interpret our observations, we used a theoretical description of mechanoelectrical transduction based on the gating spring theory and a motor model of adaptation. Simulations could account for the characteristics of transduction currents in wild-type and mutant hair cells, both vestibular and cochlear. They led us to conclude that harmonin-b operates as an intracellular link that limits adaptation and engages adaptation motors, a dual role consistent with the scaffolding property of the protein and its binding to both actin filaments and the tip link component cadherin-23.

Keywords Cochlea $\cdot$ Hair bundle $\cdot$ Vestibule $\cdot$ Harmonin . Mechanoelectrical transduction - Adaptation · Hair cell . Vestibular system

\section{Introduction}

In the inner ear, hair cells detect deflections of their mechanosensitive hair bundle, an apical tuft of actin-filled stereocilia that are organised into rows of graded lengths. Hair bundle displacement results in a receptor potential. In response to a static stimulus, the hair cells make use of an adaptive feedback mechanism to restore their sensitivity to small stimuli. This adaptation manifests itself in the form of a decrease in the transduction current evoked by a step deflection of the hair bundle $[13,16,30]$.

The prevailing theory of mechanoelectrical transduction states that tension in "gating springs" controls the open probability of transducer channels [13]. There is strong evidence to suggest that the tip link, an oblique filament connecting the tip of a short stereocilium to the side of its tallest neighbour or a more compliant link in series with the tip link functions as the gating spring [5, 39]. Recent evidence from rat cochlear hair cells indicates that the transducer channel(s) are located near the lower end of the tip link [7]. It has been proposed that the gating spring is set under tension by myosin motor molecules that dynamically anchor the upper end of the tip link to the stereocilium actin core [22]. Adaptation can readily be interpreted within the framework of this motor model. An abrupt hair bundle deflection that increases gating spring tension opens transduction channels and evokes a displacement of the motors towards the base of the stereocilia. This adaptive movement of the motors is expected to relax gating spring tension, inducing reclosure of the transduction channels [3]. Because adaptation is incomplete, the existence of an elastic link anchoring the upper end of the tip link to the stereocilium actin core has also been inferred. This extent spring would prevent the motors from fully relaxing stimulus-evoked changes in gating spring tension [41]. Both the resting open probability and adaptation kinetics depend on calcium [4, $13-15,17]$. In the motor model of adaptation, $\mathrm{Ca}^{2+}$ ions may decrease the tension exerted on the tip link by myosins [23]. If the transduction channels are somewhat distant from the motor site, as a recent study suggests [7], the kinetics of $\mathrm{Ca}^{2+}$ feedback might be limited, at least for high-frequency auditory hair cells, by the diffusion and buffering of $\mathrm{Ca}^{2+}$ ions that flow into the cell through these channels. In another model that does not suffer from this limitation, $\mathrm{Ca}^{2+}$ ions may bind to the transduction channel (or to a regulatory molecule in its close proximity) to stabilise its closed state. In this case, an increase of the transduction current would directly promote channel reclosure $[8,11,12,15,40]$.

The biophysical properties of transduction in the inner ear have been extensively characterised, but little is known about the molecular components of the transduction machinery. However, recent studies have provided immunochemical and biochemical evidence that the tip link consists of cadherin- 23 and protocadherin- 15 that form its upper and lower parts, respectively [2, 26, 43]. Harmonin is a submembranous protein containing PDZ domains that is encoded by the gene responsible for Usher syndrome type 1C (USH1C), a disease characterised by congenital profound deafness and vestibular dysfunction and delayed onset retinopathy leading to blindness. Harmonin consists of three classes of isoforms [9, 48]. Harmonin-b isoforms are the largest ones, as they contain three PDZ domains, two coiled-coil domains and a proline, serine and threoninerich domain [48]. Harmonin-b is an actin-binding protein [10] located in the region of the tip link upper insertion point in cochlear hair cells after postnatal day 5 (P5) [20, 32]. We thus assessed the role of harmonin-b in the mechanoelectrical transduction process by comparing currents evoked by mechanical stimulation of the hair bundle in wild-type mice and $U s h 1 c^{\text {dfcr-2J/dfr-2J }}$ mutant mice that lack harmonin-b isoforms only [25].

\section{Materials and methods}

Animal experiments were carried out in accordance with the Institut de la Santé et de la Recherche Médicale (INSERM) animal welfare guidelines, approved by the French Ministère de l'Agriculture, de l'Alimentation, de la Pêche et de la Ruralité. 
Antibodies

The H1b antibody used to detect harmonin-b has been described [10]. Secondary antibodies were Alexa 488conjugated goat anti-rabbit Fab 2 (1:500; Molecular Probe), Cy3-conjugated goat anti-mouse and Cy5-conjugated goat anti-rabbit (1:500; Amersham). Tetramethylrhodamine isothiocyanate-conjugated phalloidin (1:1000; Sigma) was used to label actin filaments.

Whole-mount immunofluorescence

Mouse inner ears were dissected from temporal bones at different developmental stages. The cochlear shell was pierced at its apex; the round and oval windows were opened. Inner ears were then immersed in a $4 \%$ paraformaldehyde/phosphate-buffered saline (PBS) solution for $1 \mathrm{~h}$ at room temperature. After several washes in PBS, the cochlear shell was finely dissected, and the organ of Corti was processed as described [37]. Fluorescence images were obtained with a confocal microscope (Zeiss LSM 510 META) equipped with a Plan Apochromat $63 \mathrm{x} / 1,4$ oil immersion objective. Z-stack images were deconvoluted and reconstructed with the Huygens (Scientific Volume Imaging, Hilversum, The Netherlands) and Image J (Rasband WS, US NIH, Bethesda, MA, USA, http://rsb.info. nih.gov/ij/, 1997-2006) softwares, respectively.

\section{Scanning electron microscopy}

Inner ears from $\mathrm{P} 7$ wild-type and $U s h 1 c^{\mathrm{dfcr}-2 \mathrm{~J} / \mathrm{dfcr}-2 \mathrm{~J}}$ mice were removed, pierced at the apex of the cochlea and in the round and oval windows and fixed by immersion in $2.5 \%$ glutaraldehyde in $0.1 \mathrm{M}$ phosphate buffer $(\mathrm{pH} 7.3)$ for $2 \mathrm{~h}$ at room temperature. After three washes with the buffer alone, the inner ears were dissected to give direct access to the organ of Corti or the utricle. The samples were then dehydrated by successive washes in ethanol $(50 \%, 70 \%$, $80 \%, 90 \%$ and $100 \%$ ), critical point dried, mounted on a stub, sputter coated with gold-palladium and examined under a Jeol JSM 6700F scanning microscope.

Angular deviations were measured between the expected and effective positions of the kinocilia at the apical surfaces of hair cells from the cochlear apical turn, using the graphic tools of the Jeol JSM6700F software. Briefly, for each hair cell, the kinociliary deviation was determined by the angle formed by two crossing lines. The first line was drawn mediolaterally along the symmetry/ planar cell polarity axis of the cell, thereby running through the expected position of the kinocilium. The second line was traced between the centre of the hair cell surface and the effective position of the kinocilium. Data were analysed using Excel (Microsoft).
Electrophysiological recordings with a rigid glass rod

Electrophysiological recordings and hair bundle stimulations were performed in cochlear and utricular explants from C57BL6 and Ush1 $c^{\mathrm{dfcr}-2 \mathrm{~J} / \mathrm{dfcr}-2 \mathrm{~J}}$ mice aged between $\mathrm{P} 1$ and P7 (cochlear hair cells, $n=381$ ) or between E17.5 and P1 (vestibular hair cells, $n=63$ ) as reported [36]. Briefly, the cochlear coils or utricles were finely dissected, placed under two nylon meshes and observed under a $\times 40$ waterimmersion Olympus objective mounted on an Axioscope Zeiss microscope. We recorded from cochlear outer hair cells (OHCs) that were located at a distance of approximately $50 \%$ of the total length of the cochlea, except for P7 hair cells $(35 \%$ of the length of the cochlea from the apex). Extracellular and dissecting solutions were identical and composed of $146 \mathrm{mM} \mathrm{NaCl}, 5.8 \mathrm{mM} \mathrm{KCl}, 1.5 \mathrm{mM} \mathrm{CaCl}_{2}$, $0.7 \mathrm{mM} \mathrm{NaH} 2 \mathrm{PO}_{4}, 2 \mathrm{mM}$ Na-pyruvate, $10 \mathrm{mM}$ glucose and $10 \mathrm{mM} N$-2-hydroxyethylpiperazine- $N$-2-ethanesulfonic acid (HEPES; $\mathrm{pH}=7.4,305 \mathrm{mosmol} / \mathrm{kg}$ ). Intracellular solution contained $130 \mathrm{mM} \mathrm{KCl}, 10 \mathrm{mM} \mathrm{NaCl}, 3.5 \mathrm{mM} \mathrm{MgCl}$, $1 \mathrm{mM}$ ethyleneglycoltetraacetic acid (EGTA), $5 \mathrm{mM} \mathrm{K} \mathrm{K}_{2} \mathrm{ATP}$, $0.5 \mathrm{mM} \mathrm{GTP}$ and $5 \mathrm{mM}$ HEPES ( $\mathrm{pH}=7.3,290 \mathrm{mosmol} / \mathrm{kg}$ ).

Borosilicate patch pipettes (2-3 M 2 ) were approached parallel to the hair cell rows through a hole in the reticular lamina. During this step, extracellular solution was abundantly perfused to avoid contact between EGTA and the transduction apparatus which is sensitive to calcium chelators. Hair cells were whole-cell voltage clamped at room temperature $\left(20-25^{\circ} \mathrm{C}\right)$ at $-80 \mathrm{mV}$ using an EPC-9 patch clamp amplifier and the Patchmaster software (HEKA, Lambrecht, Germany). No correction was made for liquid junction potential. Series resistance was always below $10 \mathrm{M} \Omega$ and was compensated to $70 \%$. Hair cells of the vestibular utricle (UHCs) were patched at P1. Data were sampled at $100 \mathrm{kHz}$ and filtered at $10 \mathrm{kHz}$ (8-pole Bessel). Each transducer current presented in the figures is the average response of ten consecutive stimulations.

Each hair bundle was mechanically stimulated by applying axial step displacements with a rigid glass rod that had been fire-polished prior to the experiment to yield a tip diameter of $2-3 \mu \mathrm{m}$. The probe was systematically positioned against the top of the hair bundle in the bundle's plane of bilateral symmetry towards the tallest row of stereocilia at an angle of $\sim 30^{\circ}$ relative to the cell apical surface. The probe was secured to a stack-type piezoelectric actuator (PA8/12, Piezosystem Jena, Jena, Germany) driven by a low-voltage power supply (12V40, Piezosystem Jena). To limit resonance of the actuator, a voltage ramp lasting $300 \mu \mathrm{s}$ was applied at the onset and offset of each voltage step command to the piezo-driver. As measured offline with a displacement monitor containing photodiodes [46], the first $2 \mathrm{~ms}$ of the time course of probe motion were well described by an exponential rise with a time constant of 
$490 \mu$ s. The stimulus onset was fast compared to adaptation kinetics in UHCs but relatively slow when compared to adaptation in hair bundles of the OHCs.

\section{Electrophysiological recordings with a fluid jet}

In wild-type and Ush1c $c^{-1}$ OHCs from the apical coil, mechanoelectrical transducer currents were also elicited using fluid jet stimulation $(45 \mathrm{~Hz}$ sinewaves filtered at $1 \mathrm{kHz}, 8$-pole Bessel) and recorded under whole-cell voltage clamp with an Optopatch (Cairn Research, Faversham, UK) patch clamp amplifier as described [30]. The driver voltage to the fluid jet was fixed at $40 \mathrm{~V}$, which elicits large, near-saturating transducer currents in control cells. Patch pipettes (resistance in the bath, 2-3 M $\Omega$ ) were pulled from soda glass capillaries and coated with wax. Data were filtered at $2.5-3.0 \mathrm{kHz}$ and sampled at $5 \mathrm{kHz}$ using a Power 1401 data acquisition interface and Signal 3 software (CED, Cambridge, UK).

In the case of fluid jet stimulation of the hair bundle, experimental conditions were the following. Extracellular solution contained: $135 \mathrm{mM} \mathrm{NaCl}, 5.8 \mathrm{mM} \mathrm{KCl}, 1.3 \mathrm{mM}$ $\mathrm{CaCl}_{2}, 0.9 \mathrm{mM} \mathrm{MgCl}, 0.7 \mathrm{mM} \mathrm{NaH} \mathrm{PO}_{4}, 2 \mathrm{mM} \mathrm{Na}-$ pyruvate, $5.6 \mathrm{mM}$ D-glucose and $10 \mathrm{mM}$ HEPES; amino acids and vitamins for Eagle's minimum essential medium (MEM) were added from concentrates (Invitrogen); $\mathrm{pH}$ was adjusted to 7.5 ; osmolality was about $308 \mathrm{mosmol} / \mathrm{kg}$. Intracellular solution contained: $137 \mathrm{mM} \mathrm{CsCl}, 10 \mathrm{mM}$ $\mathrm{Na}_{2}$ phosphocreatine, $2.5 \mathrm{mM} \mathrm{MgCl} 2,1 \mathrm{mM}$ EGTA$\mathrm{CsOH}, 2.5 \mathrm{mM} \mathrm{Na}$-ATP and $5 \mathrm{mM}$ HEPES; $\mathrm{pH}$ was adjusted to 7.3 with $1 \mathrm{M} \mathrm{CsOH}$; osmolality was about $295 \mathrm{mosmol} / \mathrm{kg}$.

\section{FM1-43 dye labelling}

FM1-43 dye loading experiments of hair cells in cochlear explants from neonatal wild-type and $U \operatorname{sh} 1 c^{-/-}$mice were performed as described by Gale et al. [18].

\section{Data analysis}

Data were analysed using the Igor Pro software (Wavemetrics, Portland, OR). $P_{\mathrm{o}}(X)$ curves were fitted with a three-state Boltzmann relation [6, 29, 36]. For sensitivity measurements, the mean value of the three-state Boltzmann relation derivative was calculated for displacements corresponding to $P_{\mathrm{o}}$ values between 0.2 and 0.8 . The adaptive decline of the transduction current $I$ as a function of time $t$ was fitted by the double exponential relation $I(t)=A_{\mathrm{F}}\left\{\exp \left(-\left(t-t_{0}\right) / \tau_{\mathrm{F}}\right)\right\}+A_{\mathrm{S}}\left\{\exp \left(-\left(t-t_{0}\right) / \tau_{\mathrm{S}}\right)\right\}+A_{\mathrm{SS}}$. There, $t_{0}$ is the time at which the stimulus was applied, the fast and slow components of adaptation are characterised by their magnitudes, $A_{\mathrm{F}}$ and $A_{\mathrm{S}}$, and time constants, $\tau_{\mathrm{F}}$ and
$\tau_{\mathrm{S}}$, respectively, and $A_{\mathrm{SS}}$ describes the transduction current at steady state. From the fit, we thus deduced the fast and slow adaptation rates, $1 / \tau_{\mathrm{F}}$ and $1 / \tau_{\mathrm{S}}$, and proportions, $A_{\mathrm{F}} /\left(A_{\mathrm{F}}+A_{\mathrm{S}}\right)$ and $A_{\mathrm{S}} /\left(A_{\mathrm{F}}+A_{\mathrm{S}}\right)$, respectively, as well as the extent of adaptation $1-A_{\mathrm{SS}} /\left(A_{\mathrm{F}}+A_{\mathrm{S}}+A_{\mathrm{SS}}\right)$ [27]. Only cells that had transduction currents with a maximal amplitude over $100 \mathrm{pA}$ were considered for analysis of the kinetics and extent of adaptation.

Statistical significance was tested by using either oneway analysis of variance (one-way ANOVA) coupled to the Tukey honestly significant difference post-test using the Igor Pro software, two-way analysis of variance (two-way ANOVA) coupled to the Bonferroni post-test or two-tailed unpaired $t$ test with Welch's correction using Prism software (GraphPad, La Jolla, CA). For variance comparison, we used the Fisher-Snedecor statistical test (Fig. 5). For correlation tests, we used the Pearson two-tailed correlation test. Statistical significances are indicated on the figures; $(\mathrm{ns}),(*),(* *)$ and $(* * *)$ correspond to non-significant $(p>$ $0.05), p<0.05, p<0.01$ and $p<0.001$, respectively.

\section{Simulations}

We used a physical description of transduction that takes into consideration three elements only: an intrinsic forcedisplacement relation for the hair bundle that contains a nonlinear region of reduced slope as the result of gating compliance, adaptation motors that exert an active force against gating springs, and electromechanical feedback of the $\mathrm{Ca}^{2+}$-ion component of the transduction current on the force that the adaptation motor can produce at stall $[34,35$, 46]. The dynamic interplay between the positions $X$ of the hair bundle and $X_{\mathrm{a}}$ of the adaptation motor is described by two coupled equations:

$\lambda \frac{d X}{d t}=-T_{\mathrm{GS}}\left(X, X_{\mathrm{a}}\right)-K_{\mathrm{SP}} X+F$

$\lambda_{\mathrm{a}} \frac{d X_{\mathrm{a}}}{d t}=T_{\mathrm{GS}}\left(X, X_{\mathrm{a}}\right)-K_{\mathrm{ES}}\left(X_{\mathrm{a}}-X_{\mathrm{ES}}\right)-F_{\mathrm{a}}$

The external force $F$ is applied at the hair bundle's top along the horizontal axis of a hair bundle's vertical plane of bilateral symmetry. All variables are here expressed along this axis. Hair bundle deflections $\delta X$ are related to changes in gating spring extension $\delta x$ by a geometrical gain $\gamma=\delta x / \delta X$. In the absence of gating springs, the hair bundle is at position $X=0$. The displacements of the adaptation motor are measured with respect to a position $X_{\mathrm{a}}=0$ for which the gating springs bear no tension if $X=0$ and the channels are all closed. We assume that $N$ identical transduction elements, each comprising a gating spring attached to a single transduction channel, operate in parallel 
[28]. The open probability $P_{\mathrm{o}}$ of the transduction channels is a sigmoidal function of the relative position between the hair bundle and the adaptation motor:

$$
P_{\mathrm{o}}=\frac{1}{1+A \exp \left(-\frac{K_{\mathrm{GS}} D}{N k_{\mathrm{B}} T}\left(X-X_{\mathrm{a}}\right)\right)}
$$

Here, $A=\exp \left(\left[\Delta G+\left(K_{\mathrm{GS}} D^{2}\right) /(2 N)\right] / k_{\mathrm{B}} T\right)$ accounts for an intrinsic energy difference $\Delta G=10 \mathrm{k}_{\mathrm{B}} \mathrm{T}$ between the open and the closed states of a transduction channel, in which $k_{\mathrm{B}}$ is the Boltzmann constant and $T$ the temperature.

Equation 1 describes the dynamical behaviour of the hair bundle position $X$ in response to the external force $F$. The hair bundle moves at a velocity that is inversely proportional to the friction coefficient $\lambda$. At steady state $(d X / d t=$ $0), F$ is balanced by the sum of the elastic restoring force $K_{\mathrm{SP}} X$ provided by the stereociliary pivots and the total tension $T_{\mathrm{GS}}=K_{\mathrm{GS}}\left(X-X_{\mathrm{a}}-D P_{\mathrm{o}}\right)$ in the gating springs. Here, $K_{\mathrm{GS}}$ and $K_{\mathrm{SP}}$ correspond to the stiffness of the gating springs and of the stereociliary pivots, respectively. Channel opening decreases gating spring extension by a distance $d$ that amounts to a horizontal displacement $D=d / \gamma$ at the top of the bundle. Equation 2 describes the dynamical behaviour of the adaptation motor by a linear forcevelocity relation of slope $\lambda_{\mathrm{a}}$. At stall $\left(d X_{\mathrm{a}} / d t=0\right)$, the active motor force $F_{\mathrm{a}}$ is balanced by the combined tension in gating springs and extent springs of stiffness $K_{\mathrm{ES}}$. The extent springs anchor the transduction apparatus to the stereociliary cytoskeleton and account for the incompleteness of adaptation [41]. In Eq. 2, $X_{\mathrm{ES}}$ is the value of $X_{\mathrm{a}}$ for which the extent springs bear no tension. To account for the regulation of adaptation by $\mathrm{Ca}^{2+}$ ions [16], we assume that the force produced by the motors at stall depends on the $\mathrm{Ca}^{2+}$ concentration at the motor site. Under the simplifying assumption that $\mathrm{Ca}^{2+}$ diffusion to this site and that binding and unbinding kinetics of $\mathrm{Ca}^{2+}$ ions to the motors are fast compared to the timescale of adaptation, this $\mathrm{Ca}^{2+}$ feedback is effectively instantaneous and approximately determined by the open probability of the transduction channels [46].

$F_{\mathrm{a}} \cong F_{\max }\left(1-S P_{\mathrm{o}}\right)$

In Eq. 4, the dimensionless parameter $S$ defines the strength of $\mathrm{Ca}^{2+}$ feedback on the motor force, and $F_{\max }$ is the force produced by the motors when the channels are all closed $\left(P_{\mathrm{o}}=0\right)$. This equation ensures that increased $\mathrm{Ca}^{2+}$ levels at the motor site reduce active force generation and thus result in lower open probabilities of the transduction channels. Note that $K_{\mathrm{GS}}$ and $K_{\mathrm{ES}}$ are each proportional to $N \gamma^{2}$, whereas $\lambda_{\mathrm{a}}$ and $F_{\text {max }}$ are proportional to $N_{\mathrm{a}} \gamma^{2}$, where $N_{\mathrm{a}}$ is the total number of adaptation motors and is thus also proportional to the number $N$ of transduction elements [34].
We assumed in simulations that an external force of the form $F=K_{\mathrm{F}}(\Delta-X)$ was applied to the hair bundle. The response of the combined system of a hair bundle and its attached stimulus fibre of stiffness $K_{\mathrm{F}}$ to a movement $\Delta$ of the fibre's base was computed by setting $F=K_{\mathrm{F}} \Delta$. For numerical calculations, parameter $K_{\mathrm{SP}}$ in turn corresponded to the summed stiffness of the stereociliary pivots and fibre, and the friction coefficient $\lambda$ includes the friction coefficient of the fibre and of the hair bundle. To mimic the displacement clamp conditions that were used in experiments, the fibre used in simulations had to be rigid compared to the hair bundle stiffness, resulting in large values of $K_{\mathrm{SP}}$. The rise time of hair bundle deflections was controlled by the ratio of $\lambda$ and $K_{\mathrm{SP}}$.

Simulations were performed in Matlab, version 7.0 (The MathWorks, Natick, MA). Calculated transduction responses were fitted with a double exponential curve to extract fast and slow adaptation rates, the proportion of fast and slow components of adaptation and the adaptation extent.

\section{Results}

Harmonin-b relocalises to the region of the tip link upper insertion point in developing utricular hair cells and cochlear outer hair cells

We analysed the distribution of harmonin-b within the hair bundles of the outer hair cells of the cochlea and hair cells of the vestibular utricle. An intense harmonin-b immunostaining restricted to the apical region of the hair bundle was observed in both UHCs and OHCs, which was absent in

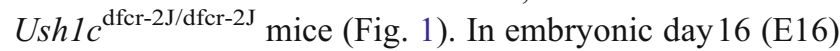
UHCs, harmonin-b immunoreactivity was found at the very tips of stereocilia, whereas at E18, it was detected below the stereocilia tips (Fig. 1a). In P3 mice, OHCs displayed a punctate harmonin-b staining at the tip of each of the stereocilia that compose the tall and middle rows, whereas stereocilia from the small row were unlabelled. Two days later, the labelling in the tall and middle rows was no longer detected at the stereocilia tips but was present farther down in the region of the tip link upper insertion point (Fig. 1b). No labelling was detected in OHC stereocilia from the small row, which do not have a tip link insertion point on their lateral wall. These results argue in favour of the relocalization of harmonin-b from the stereocilia tip to the region of the tip link upper insertion point between E16 and E18 in the UHCs and between P3 and $\mathrm{P} 5$ in the OHCs. The harmonin-b labelling pattern persisted as an intense punctate staining of the tip link upper end region in both UHCs and OHCs at mature stages (Fig. 1a, b). 
a

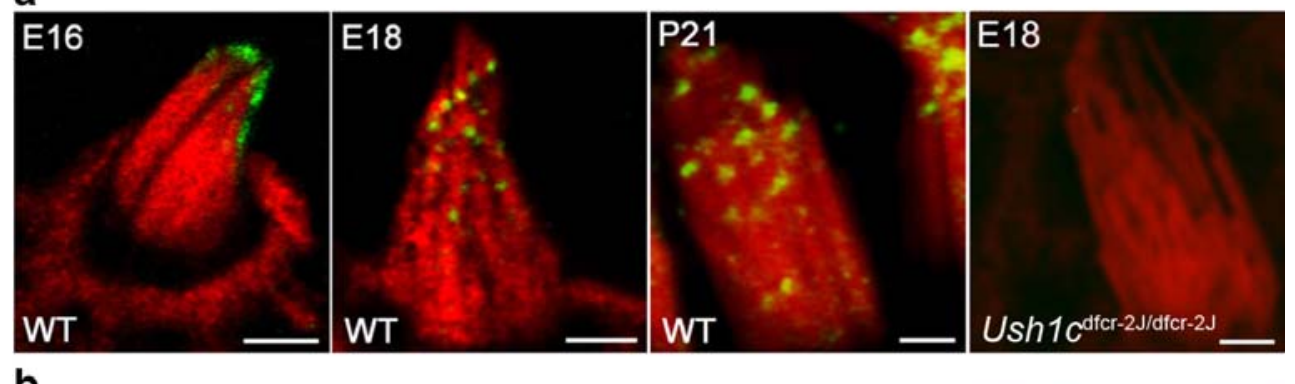

b
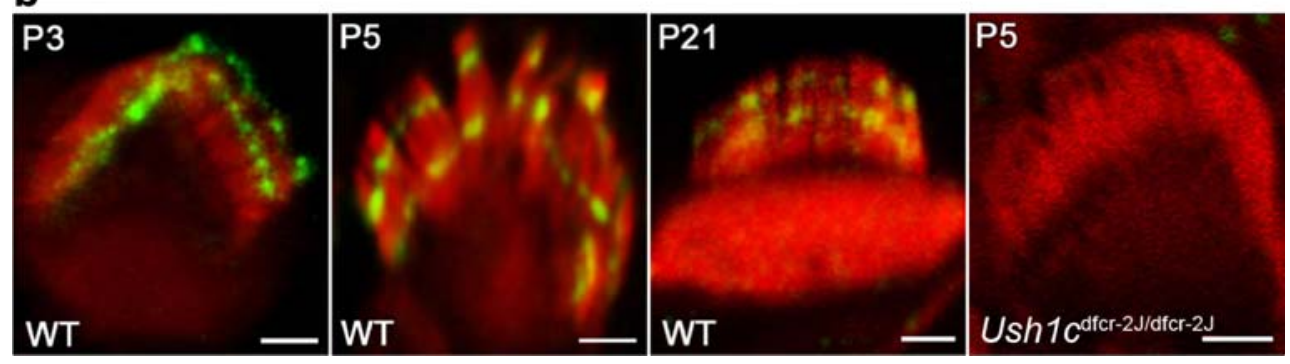

Fig. 1 Distribution of harmonin-b in UHC and $\mathrm{OHC}$ hair bundles from wild-type and $U s h 1 c^{\mathrm{dfcr}-2 \mathrm{~J} / \mathrm{dfcr}-2 \mathrm{~J}}$ mice. a UHCs. A punctate harmonin-b labelling (green) can be seen in the apical region of the stereocilia in E16, E18 and P21 wild-type UHCs (WT). The labelling is located at the stereocilia tip at E16 and below the tip at E18 and $\mathrm{P} 21$. It is not detected in $U$ sh $1 c^{\mathrm{dfcr}-2 \mathrm{~J} / \mathrm{dfcr}-2 \mathrm{~J}}$ UHCs. Actin filaments are labelled in red. b OHCs. A punctate harmonin-b labelling (green) can be seen in all stereocilia from the tall and middle rows in wild-type OHCs $(W T)$. The labelling is located at the stereocilia tip at P3 and below the tip at P5 and P21. It is not detected in Ush $1 c^{\mathrm{dfcr}-2 \mathrm{~J} / \mathrm{dfcr}-2 \mathrm{~J}}$ OHCs. Actin filaments are labelled in red. Scale bars $=1 \mu \mathrm{m}$
Maturation of transduction currents in $\mathrm{UHCs}$ and $\mathrm{OHCs}$

We studied transduction currents in wild-type mice during the period of hair bundle maturation in UHCs and OHCs. In murine UHCs, transduction onset occurs at embryonic day 17 (E17) and is already associated with fast and slow components of adaptation [19]. We analysed how transduction features evolve between E18 and P1. The mean maximum amplitude of transduction currents increased by a factor of 2.5 , from $125 \pm 26$ to $320 \pm 25 \mathrm{pA}$ (one-way ANOVA, $p<10^{-5}$ ), between E18 and P1 (Fig. 2a). By contrast, the relationship $P_{\mathrm{o}}(X)$ between open probability of the transduction channels $\left(P_{\mathrm{o}}\right)$ and hair bundle displacement $(X)$ changed very little over this period. Indeed, the averaged sensitivity of the transduction current to hair bundle displacement, defined as the mean slope of the $P_{\mathrm{o}}(X)$ curve between $P_{\mathrm{o}}=0.2$ and $P_{\mathrm{o}}=0.8$, did not vary (from $0.91 \pm 0.12 \mu \mathrm{m}^{-1}$ at E18 to $1.07 \pm 0.16 \mu \mathrm{m}^{-1}$ at P1; unpaired $t$ test, $p=0.43$ ). Only the displacement $X_{0.5}$ required for the opening of $50 \%$ of the transduction channels decreased by $23 \%$, from $644 \pm 64 \mathrm{~nm}$ at E18 to $480 \pm 40 \mathrm{~nm}$ at P1 (unpaired $t$ test, $p<0.05$; Fig. 2a). Adaptation can be characterised in terms of its extent and kinetics. The extent of adaptation (see "Materials and methods") did not change significantly between E18 and $\mathrm{P} 1$, regardless of the open probability chosen to make the comparison (two-way ANOVA, $p=0.06$; Fig. 2a). From
E18 onward, utricular transduction currents displayed an adaptive decline in two sequential phases, a rapid decline in the millisecond range, followed by a slow decline in the 5 to $100 \mathrm{~ms}$ range, as previously reported [45]. The rates of fast and slow components of adaptation (see "Materials and methods") remained unchanged between E18 and P1 (twoway ANOVA, $0.05<p<0.1$ for both adaptation rates; Fig. 2a). The only significant modification observed concerned the relative balance between the fast and slow components, with the slow component of adaptation predominating at P1 but not at E18 (two-way ANOVA, $p<0.05$ ).

A previous study has described the time course for the acquisition and maturation of transduction currents in rat cochlear OHCs maintained in organotypic cultures [49]. We thought it necessary to verify whether a similar maturation of transduction currents occurs in mouse OHCs. We thus recorded from acute preparations of the organ of Corti from mice aged between P1 and P7 (Fig. 2b). All the transduction characteristics in OHCs displayed significant maturation between these two stages. The mean maximal amplitude of transduction currents increased by a factor of 7, from $142 \pm 50$ to $968 \pm 58 \mathrm{pA}$ (one-way ANOVA, $p<$ $10^{-12}$ ), between P1 and P7 (Fig. 2b). The sensitivity of the transduction current to hair bundle displacement also increased over this period. We found that averaged sensitivity almost doubled, from $1.86 \pm 0.31 \mu^{-1}$ at $\mathrm{P} 1$ to 


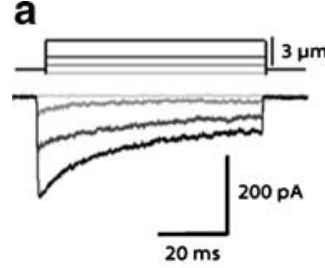

E18
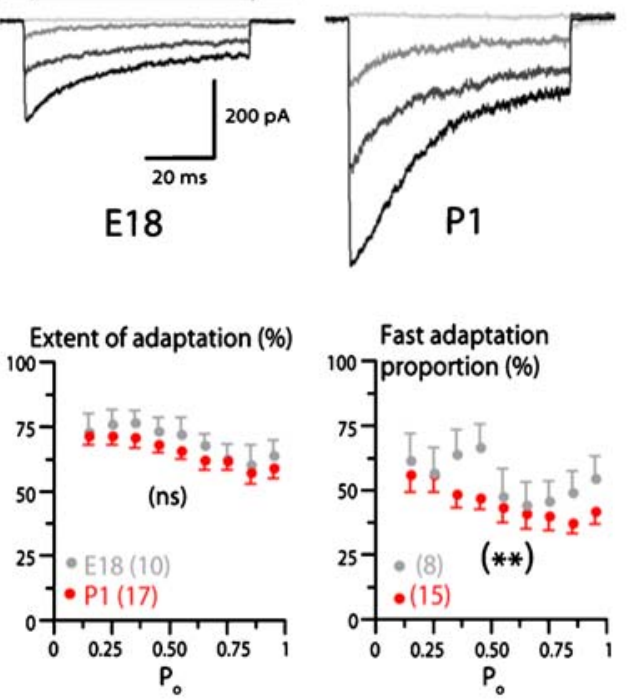

b
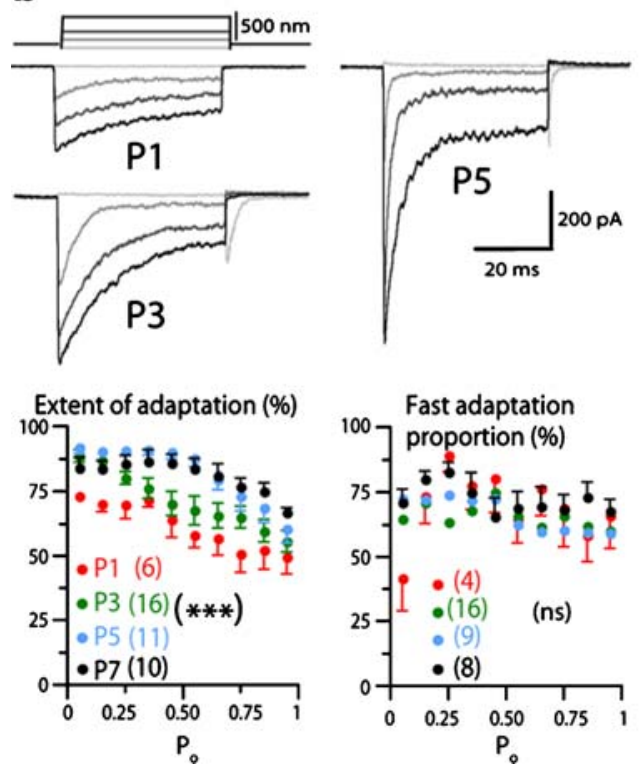

Fig. 2 Transduction current recordings in wild-type UHCs and OHCs. a Upper panels. Left Examples of transduction current recordings in UHCs voltage clamped at $-80 \mathrm{mV}$ from E18 and P1 wild-type mice while applying different displacement steps with a glass probe in the excitatory direction and one $150 \mathrm{~nm}$ step in the inhibitory direction (calibrated voltage command of the stimulator at the top left). Right Mean maximum transduction currents recorded in E18 and P1 wild-type UHCs and $P_{\mathrm{o}}(X)$ plots for E18 and P1 wild-type mice. The E18 and P1 curves were fitted with a normalised three-state Boltzmann relation: $I=1 /\left[1+\left\{\exp \left(-\left(X-X_{0}\right) / \delta_{0}\right)\right\}\right.$ $\left.\left\{1+\exp \left(-\left(X-X_{1}\right) / \delta_{1}\right)\right\}\right]$, where $\delta_{0}=474 \mathrm{~nm}, \delta_{1}=117 \mathrm{~nm}, X_{0}=$ $500 \mathrm{~nm}$ and $X_{1}=353 \mathrm{~nm}$ for E18 UHCs, and $\delta_{0}=555 \mathrm{~nm}, \delta_{1}=109 \mathrm{~nm}$, $X_{0}=213 \mathrm{~nm}$ and $X_{1}=313 \mathrm{~nm}$ for P1 UHCs. Lower panels Extent of adaptation, contribution of fast adaptation to the adaptation extent $(\%$ of fast adaptation), fast adaptation rates and slow adaptation rates plotted as a function of $P_{\mathrm{o}}$ for E18 and P1 wild-type UHCs. ${ }^{*} p<0.05$,
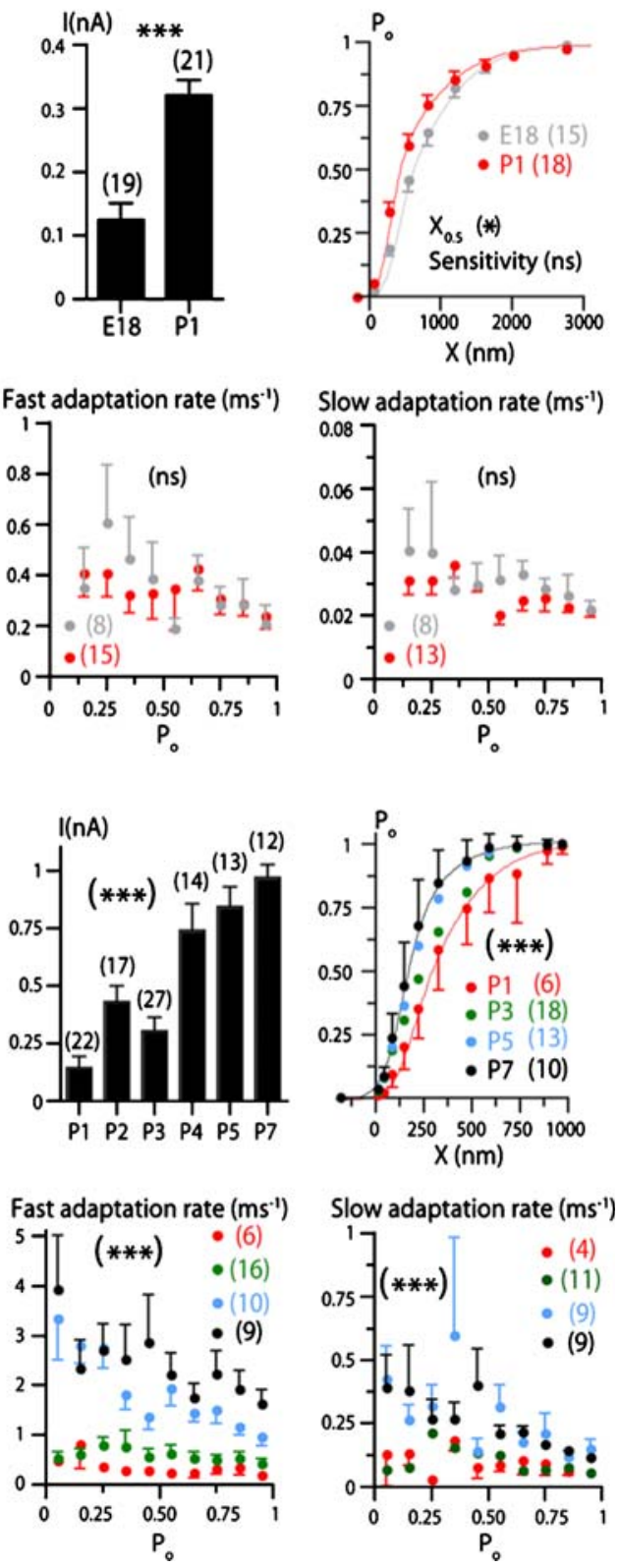

${ }^{* *} p<0.01$ statistical significance and $n s p>0.05$ non-significance. $\mathbf{b}$ Upper panels. Left Examples of transduction current recordings in OHCs voltage clamped at $-80 \mathrm{mV}$ from P1, P3 and P5 wild-type mice while applying different displacement steps with a glass probe in the excitatory direction and a $150 \mathrm{~nm}$ step in the inhibitory direction (calibrated voltage command of the stimulator at the top left). Right Mean maximum transduction currents recorded between P1 and P7 in wild-type $\mathrm{OHCs}$ and $P_{\mathrm{o}}(X)$ plots for $\mathrm{P} 1, \mathrm{P} 3, \mathrm{P} 5$ and $\mathrm{P} 7$ wild-type mice. The P1 and P7 curves were fitted with a three-state Boltzmann relation: $I=1 /\left[1+\left\{\exp \left(-\left(X-X_{0}\right) / \delta_{0}\right)\right\}\{1+\exp (-\right.$ $\left.\left.\left.\left(X-X_{1}\right) / \delta_{1}\right)\right\}\right]$, where $\delta_{0}=192 \mathrm{~nm}, \delta_{1}=67 \mathrm{~nm}, X_{0}=255 \mathrm{~nm}$ and $X_{1}=$ $176 \mathrm{~nm}$ for P1 OHCs and $\delta_{0}=159 \mathrm{~nm}, \delta_{1}=63 \mathrm{~nm}, X_{0}=47 \mathrm{~nm}$ and $X_{1}=$ $173 \mathrm{~nm}$ for P7 OHCs. Lower panels Extent of adaptation, contribution of fast adaptation to the adaptation extent ( $\%$ of fast adaptation), fast adaptation rates and slow adaptation rates plotted as a function of $P_{\mathrm{o}}$ for P1, P3, P5 and P7 wild-type OHCs 
$3.29 \pm 0.29 \mu^{-1}$ at P7 (unpaired $t$ test, $p<10^{-2}$ ), while $X_{0.5}$ decreased by a factor of 2 , from $314 \pm 34 \mathrm{~nm}$ at $\mathrm{P} 1$ to $165 \pm$ $12 \mathrm{~nm}$ at $\mathrm{P} 7$ (unpaired $t$ test, $p<10^{-4}$; Fig. 2b). Adaptation also varied between P1 and P7. The extent of adaptation increased over this period (two-way ANOVA, $p<10^{-4}$ ), more markedly for intermediate open probabilities than near $P_{\mathrm{o}}=0$ or 1 (Fig. 2b). Thus, although the extent of adaptation at P1 decreased almost linearly as a function of $P_{\mathrm{o}}$, it was almost invariant at $\mathrm{P} 7$ for $P_{\mathrm{o}}<0.5$. The $\mathrm{OHC}$ transduction currents displayed two sequential phases of adaptive decline: a fast phase in the submillisecond range, followed by a slow phase, in the 5 to $100 \mathrm{~ms}$ range, as previously reported $[27,29,44,49]$. Fast and slow adaptation rates increased between P1 and P7. Increases by a factor of almost 10 for the fast adaptation rate and of almost 4 for the slow adaptation rate were observed between $\mathrm{P} 1$ and P7, for $P_{\mathrm{o}}=0.5$ (two-way ANOVA, $p<$ $10^{-4}$ for both adaptation rates; Fig. 2b). Adaptation speeds, which were independent of $P_{\mathrm{o}}$ until P3, subsequently became faster for small $P_{\mathrm{o}}$. Notably, the maximal transduction current, as well as the extent and speed of adaptation, underwent greater changes between P3 and P5 than between P1 and P3 or P5 and P7 (Fig. 2b). We conclude that the transduction currents recorded from mouse acute preparations of the organ of Corti reproduce the stepwise functional maturation which has been observed in rat organotypic cultures [49]. Our findings are also in agreement with those recently obtained on mouse OHCs by [33].

Adaptation is more complete and slightly faster in Ush $1 c^{\mathrm{dfcr}-2 \mathrm{~J} / \mathrm{dfcr}-2 \mathrm{~J}} \mathrm{UHCs}$

We compared the characteristics of transduction currents in $U \operatorname{sh} 1 c^{\mathrm{dfcr}-2 \mathrm{~J} / \mathrm{dfcr}-2 \mathrm{~J}}$ and wild-type $\mathrm{UHCs}$ at $\mathrm{P} 1$. Ushlc $c^{\text {dfcr-2J/dfr-2J }} \mathrm{UHC}$ hair bundles display no detectable morphological abnormalities at this stage (Fig. 3). Many of the transduction properties were unaffected in the mutant UHCs. In particular, the amplitudes of the transduction current were similar to those for the wild type (one-way ANOVA, $p>0.05$; Fig. $4 b$ ). In addition, no change in averaged sensitivity or $X_{0.5}$ could be detected in the mutant UHCs (unpaired $t$ test, $p=0.11$ and $p=0.07$, respectively; Fig. 4c). Accordingly, the $P_{\mathrm{o}}(X)$ curves of $U$ sh $1 c^{\mathrm{dfcr}-2 \mathrm{~J} / \mathrm{dfcr}-2 \mathrm{~J}}$ and wild-type UHCs could be superimposed. Yet, the extent of adaptation was significantly greater in these cells, resulting in a residual current one third lower than in wild-type UHCs (two-way ANOVA, $p<10^{-4}$; Fig. 4d). Fast and slow components of adaptation made similar contributions to the extent of adaptation in both wild-type and Ush $1 c^{\text {dfcr-2J/dfcr-2J }}$ UHCs (two-way ANOVA on fast to slow adaptation ratios, $p=0.06$; Fig. $4 \mathrm{e}$ ). The fast adaptation rate tended to be greater for all $P_{\mathrm{o}}$ in $U s h 1 c^{\mathrm{dfcr}-2 \mathrm{~J} / \mathrm{dfcr}-2 \mathrm{~J}}$ than in wild-type UHCs (Fig. 4f), but this difference was not statistically significant (two-way ANOVA, $p=0.11$ ). However, the slow adaptation rate was significantly greater in the mutant UHCs (two-way ANOVA, $p<10^{-4}$; Fig. 4f).

Ush1c dfcr-2J/dfcr-2J $\mathrm{OHCs}$ display a variable extent and slower kinetics of adaptation

We then studied transduction currents in $U$ sh $1 c^{\mathrm{dfcr}-2 \mathrm{~J} / \mathrm{dfcr}-2 \mathrm{~J}}$ OHCs at P7. In harmonin-b-deficient OHCs, the hair bundles are slightly misoriented, with a mean deviation of the kinocilium of $20^{\circ}$ (see "Materials and methods" and Fig. 3). In addition, approximately $20 \%$ of the hair bundles are fragmented in two clumps. Notably, these anomalies are far less severe than those observed in the harmonin-null $\left(U s h 1 c^{-1-}\right)$ mice [32]. We only describe transduction currents that were recorded in $U_{s h} 1 c^{\mathrm{dfcr}-2 \mathrm{~J} / \mathrm{dfcr}-2 \mathrm{~J}} \mathrm{OHCs}$ with nonfragmented hair bundles (Fig. 3). Maximal currents were, on average, only a third of those recorded in wild-type OHCs (Fig. 5a, b; unpaired $t$ test, $p<10^{-4}$ ). The averaged sensitivity of the transduction currents to hair bundle displacement was $30 \%$ lower in the mutant OHCs, with values of $3.29 \pm$ $0.29 \mathrm{\mu m}^{-1}$ obtained for wild-type OHCs, and 2.24

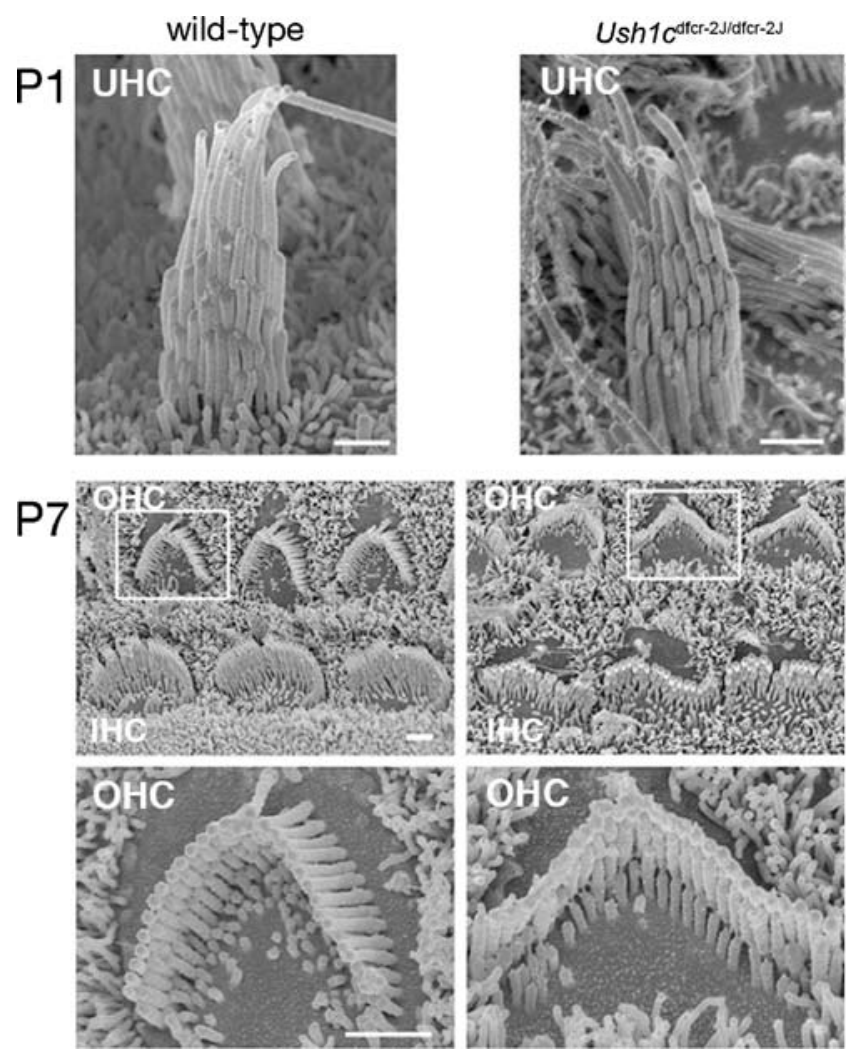

Fig. 3 Hair bundle morphology in wild-type and $U \operatorname{sh} 1 c^{\mathrm{dfcr}-2 \mathrm{~J} / \mathrm{dfcr}-2 \mathrm{~J}}$ mice. Top row Scanning electron microphotographs of utricular hair bundles from wild-type and $U s h 1 c^{\mathrm{dfcr}-2 \mathrm{~J} / \mathrm{dfcr}-2 \mathrm{~J}} \mathrm{P} 1$ mice. Middle and lower rows Scanning electron microphotographs of organs of Corti from wild-type and $U \operatorname{sh} 1 c^{\mathrm{dfcr}-2 \mathrm{~J} / \mathrm{dfcr}-2 \mathrm{~J}} \mathrm{P} 7 \mathrm{mice}$ and detail of an $\mathrm{OHC}$ hair bundle (white frames in middle row). Scale bars $=1 \mu \mathrm{m}$ 


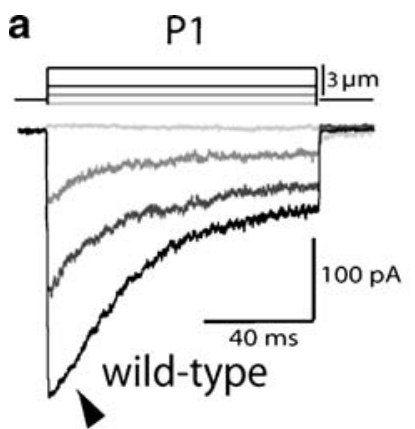

b
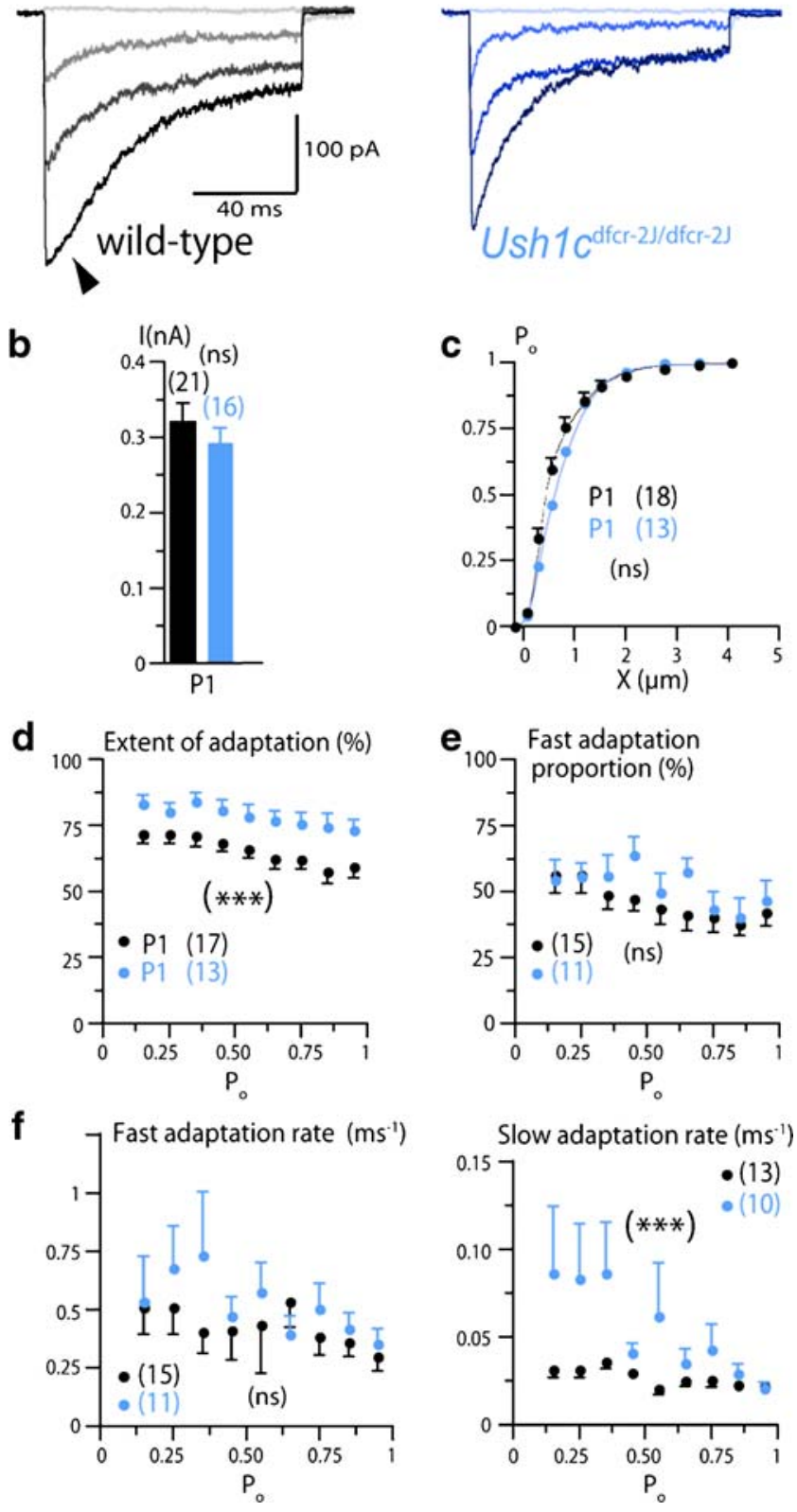

$0.13 \mu \mathrm{m}^{-1}$ for mutant OHCs (unpaired $t$ test, $p<10^{-2}$ ). In addition, $X_{0.5}$ was higher in mutant $\left(X_{0.5}=318 \pm 26 \mathrm{~nm}\right)$ than in wild-type $\left(X_{0.5}=165 \pm 12 \mathrm{~nm}\right)$ OHCs (unpaired $t$ test, $p<10^{-4}$; data not shown). We noted, however, that mutant OHCs with transduction currents larger than $450 \mathrm{pA}$ displayed an average $P_{\mathrm{o}}(X)$ curve that could be superimposed to that of the wild type (Fig. 5c). The mean extent of adaptation was smaller in Ush $1 c^{\text {dffr-2J/dfr-2J }}$ than in wildtype OHCs (two-way ANOVA, $p<10^{-4}$, Fig. 5d). A significant correlation was observed between the extent of adaptation and the maximal current amplitude: the extent of adaptation tended to increase with current amplitude (two-
Fig. 4 Mechanoelectrical transduction current recordings in Ush $1 c^{\text {dfcr-2J/dfcr-2J }}$ UHCs. a Examples of transduction current recordings in P1 wild-type (left panel) and $U$ shl $1 c^{\mathrm{dfcr}-2 \mathrm{~J} / \mathrm{dfcr}-2 \mathrm{~J}} \mathrm{UHCs}$ (right panel) voltage clamped at $-80 \mathrm{mV}$ while applying different displacement steps with a glass probe in the excitatory direction and a $150-\mathrm{nm}$ step in the inhibitory direction (calibrated voltage command of the stimulator at the top left). We noticed that, in some cells, saturating stimuli evoked adaptive currents that displayed a sigmoidal time course and were thus poorly described by a double exponential (arrowhead). b Mean maximum transduction currents recorded in P1 wild-type and $U s h 1 c^{\mathrm{dfcr}-2 \mathrm{~J} / \mathrm{dfcr}-2 \mathrm{~J}}$ UHCs. c $P_{\mathrm{o}}(X)$ curves plotted for P1 wild-type and $U s h 1 c^{\mathrm{dfcr}-2 \mathrm{~J} / \mathrm{dfcr}-2 \mathrm{~J}}$ UHCs. $P_{\mathrm{o}}(X)$ curves were fitted with a normalised three-state Boltzmann relation: $I=1 /\left[1+\left\{\exp \left(-\left(X-X_{0}\right) /\right.\right.\right.$ $\left.\left.\left.\delta_{0}\right)\right\}\left\{1+\exp \left(-\left(X-X_{1}\right) / \delta_{1}\right)\right\}\right]$, where $\delta_{0}=555 \mathrm{~nm}, \delta_{1}=109 \mathrm{~nm}, X_{0}=$ $213 \mathrm{~nm}$ and $X_{1}=313 \mathrm{~nm}$ for P1 wild-type UHCs and $\delta_{0}=385 \mathrm{~nm}, \delta_{1}=$ $108 \mathrm{~nm}, X_{0}=558 \mathrm{~nm}$ and $X_{1}=229 \mathrm{~nm}$ for P1 Ush $1 c^{\mathrm{dfcr}-2 \mathrm{~J} / \mathrm{dfcr}-2 \mathrm{~J}}$ UHCs. d Extent of adaptation curves plotted as a function of $P_{\mathrm{o}}$ for P1 wildtype and Ush $1 c^{\mathrm{dfcr}-2 \mathrm{~J} / \mathrm{dfcr}-2 \mathrm{~J}}$ UHCs. e Contribution of fast adaptation to the adaptation extent ( $\%$ of fast adaptation) plotted as a function of $P_{\mathrm{o}}$ for P1 wild-type and Ush $1 c^{\mathrm{dfcr}-2 \mathrm{~J} / \mathrm{dfcr}-2 \mathrm{~J}}$ UHCs. f Fast adaptation rates and slow adaptation rates, plotted as a function of $P_{\mathrm{o}}$ for P1 wild-type and $U s h 1 c^{\mathrm{dfcr}-2 \mathrm{~J} / \mathrm{dfcr}-2 \mathrm{~J}} \mathrm{UHCs}$

tailed Pearson's correlation test, $p<10^{-4}$ ). This correlation biased the average extent of adaptation in mutant cells towards the hypoadaptive behaviour. The most striking adaptation feature in $U s h 1 c^{\mathrm{dfcr}-2 \mathrm{~J} / \mathrm{dfr}-2 \mathrm{~J}} \mathrm{OHCs}$ was the considerable variability of the extent of adaptation (left and right panels of Fig. 5d). This property was not simply dictated by variations of the maximal transduction currents. Cells with similar transduction currents could indeed display very different adaptation extents, a behaviour that contrasts with that of wild-type cells (Fig. $5 \mathrm{~d}$ left panel). In particular, among those mutant cells that displayed the largest transduction currents $\left(I_{\max }>450 \mathrm{pA}\right)$, both hyperadaptive and hypoadaptive responses were observed (Fig. 5a, middle and right panels). Fast and slow adaptation rates were lower in mutant OHCs (two-way ANOVA, $p<10^{-4}$, Fig. 5e) and were not correlated with the transduction current amplitude (data not shown). In addition, the fast component of adaptation contributed a lesser fraction of the extent of adaptation in the mutant OHCs (two-way ANOVA, $p<10^{-4}$, Fig. 5e).

We were concerned that morphological defects, albeit minimal in the hair bundles that we selected for recording (Fig. 3), could be responsible for the variations of transduction characteristics that we observed in mutant OHCs. We thus carried out a series of control experiments. First, we measured the rise time of the transduction current in wildtype and Ush $1 c^{\text {dfcr-2J/dfr-2J } O H C s . ~ A c t i v a t i o n ~ k i n e t i c s ~ o f ~ t h e ~}$ transduction channels indeed has an influence on adaptation characteristics [50]. We did not, however, observe any statistically significant difference between mutant $\mathrm{OHCs}$ that hypoadapted and OHCs that hyperadapted, and also checked that activation kinetics were similar in mutant and wild-type hair cells (data not shown). This ensured that mechanical coupling of the stimulating probe was as tight with mutant as 

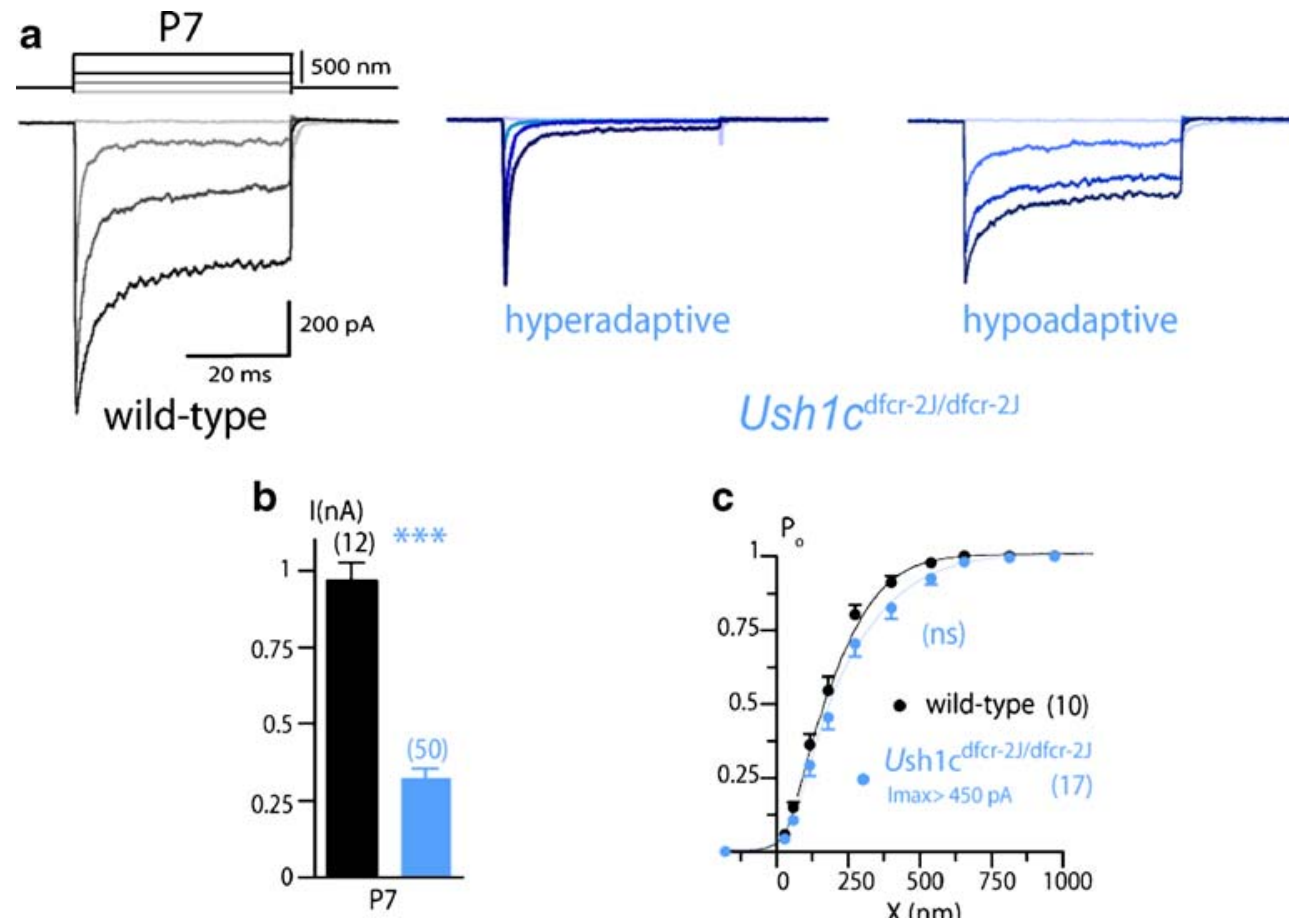

Ush $1 C^{\mathrm{dfcr}-2 \mathrm{~J} / \mathrm{dfcr}-2 \mathrm{~J}}$
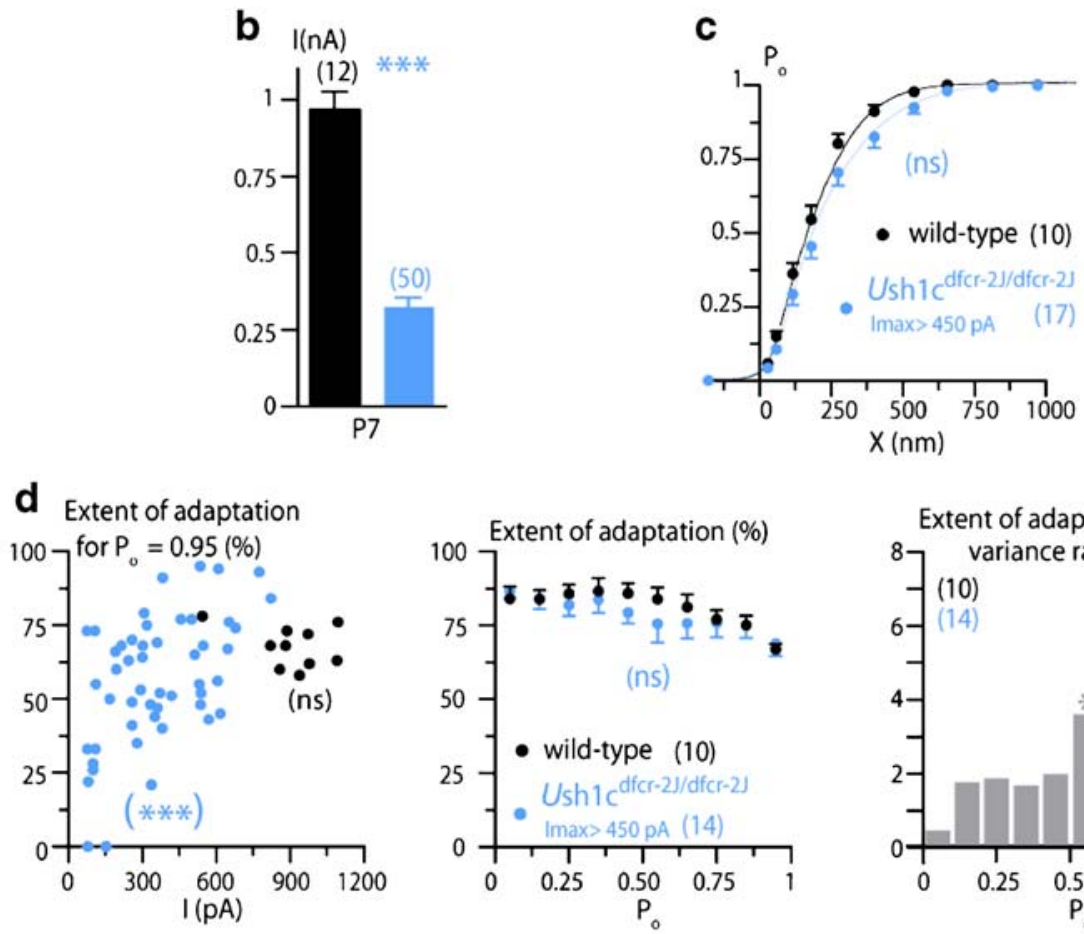

Extent of adaptation
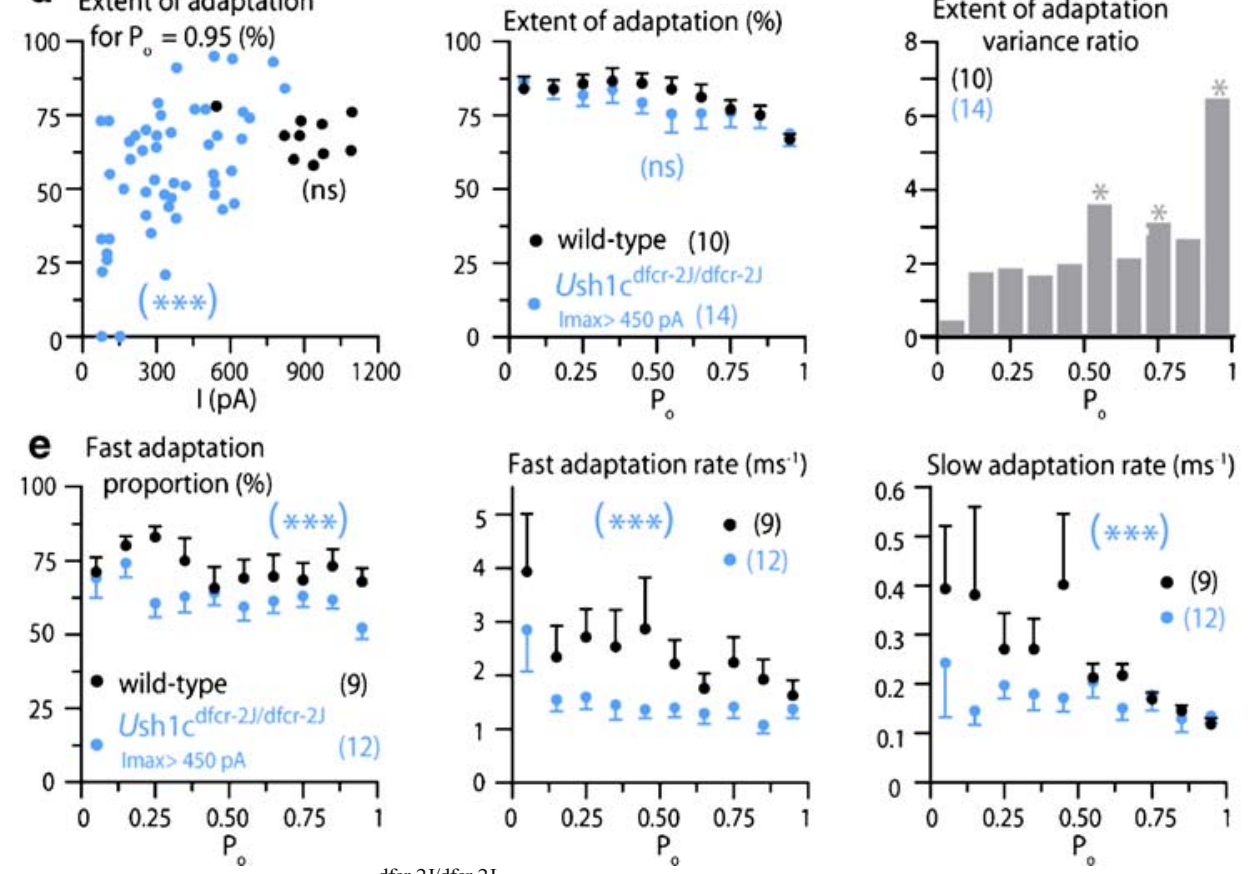

Fig. 5 Transduction current recordings in $U \operatorname{sh} 1 c^{\text {dfcr-2J/dfcr-2J }}$ OHCs. a Examples of transduction current recordings in a wild-type OHC (left panel), a hyperadaptive Ushlc $c^{\mathrm{dfcr}-2 \mathrm{~J} / \mathrm{dfr}-2 \mathrm{~J}} \mathrm{OHC}$ (middle panel) and a hypoadaptive Ushl $c^{\text {dfcr-2J/dfcr-2J }} \mathrm{OHC}$ (right panel) voltage clamped at $-80 \mathrm{mV}$ from P7 mice while applying different displacement steps with a glass probe in the excitatory direction and a $150-\mathrm{nm}$ step in the inhibitory direction (calibrated voltage command of the stimulator at the top left). $\mathbf{b}$ Mean maximum transduction currents recorded in P7 wild-type and $U$ sh $1 c^{\text {dfcr-2J/dfr-2J }}$ OHCs. c $P_{\mathrm{o}}(X)$ curves plotted for P7 wild-type and $U s h 1 c^{\text {dfcr-2J/dfr-2J }} \mathrm{OHCs}$ with an $I_{\max }$ superior to $450 \mathrm{pA}$. $P_{\mathrm{o}}(X)$ curves were fitted with a normalised three-state Boltzmann relation: $I=1 /[1+\{\exp$ $\left.\left.\left(-\left(X-X_{0}\right) / \delta_{0}\right)\right\}\left\{1+\exp \left(-\left(X-X_{1}\right) / \delta_{1}\right)\right\}\right]$, where $\delta_{0}=91 \mathrm{~nm}, \delta_{1}=31 \mathrm{~nm}, X_{0}=$ $153 \mathrm{~nm}$ and $X_{1}=64 \mathrm{~nm}$ for P7 wild-type OHCs and $\delta_{0}=143 \mathrm{~nm}, \delta_{1}=$
$47 \mathrm{~nm}, X_{0}=162 \mathrm{~nm}$ and $X_{1}=111 \mathrm{~nm}$ for P7 Ush $1 c^{\text {dfcr-2J/dfcr-2J }}$ OHCs with an $I_{\max }$ superior to $450 \mathrm{pA}$. d Left panel Extent of adaptation for $P_{\mathrm{o}}=95 \%$ plotted as a function of amplitude for each wild-type or $U s h 1 c^{\mathrm{dfcr}-2 \mathrm{~J} / \mathrm{dfcr}-2 \mathrm{~J}}$ OHC. Correlation was estimated using Pearson's test. Middle panel Extent of adaptation curves plotted as a function of $P_{\mathrm{o}}$ for P7 wild-type and $U s h 1 c^{\text {dfcr-2J/dfcr-2J }}$ OHCs with an $I_{\max }$ superior to $450 \mathrm{pA}$. Right panel Variance ratios between the extent of adaptation of $U s h 1 c^{\text {dfcr-2J/dfcr-2J }}$ with an $I_{\max }$ superior to $450 \mathrm{pA}$ and wild-type OHCs plotted as a function of $P_{\mathrm{o}}$. The statistical significance for the variance ratio was estimated using the Fisher-Snedecor tables. e Contribution of fast adaptation to the adaptation extent ( $\%$ of fast adaptation), fast adaptation rates and slow adaptation rates, plotted as a function of $P_{\mathrm{o}}$ for $\mathrm{P} 7$ wild-type and $U$ sh $1 c^{\mathrm{dfcr}-2 \mathrm{~J} / \mathrm{dfcr}-2 \mathrm{~J}} \mathrm{OHCs}$ with an $I_{\max }$ superior to $450 \mathrm{pA}$ 
Fig. 6 Mechanoelectrical transduction current recordings in Ushlc OHCs. a Examples of transducer current recordings in OHCs from $U$ sh $1 c^{+/}$control and $U$ sh $1 c^{-/-} \mathrm{P} 2$ mice, while applying near-saturating sinusoidal fluid jet stimuli (methods as in [47]). Upper panels Current traces for different membrane potentials $(-120 \mathrm{mV}$ to $120 \mathrm{mV})$. Note the absence of resting transduction currents in Ushlc $c^{-/}$OHCs. Lower panel Corresponding current-voltage curves. b Examples of transducer current recordings in OHCs from wild-type, Ush $1 c^{-1} \mathrm{P} 3$ and $U$ sh $1 c^{-/}$ P7 mice, while applying stiff fibre stimuli. c FM1-43 dye loading of hair cells in cochlear explants from wild-type and Ush1c ${ }^{--}$P2 mice (upper panels). Images were captured 15 min after a 10-s dip in $3 \mu \mathrm{M}$ FM1-43. DIC images of the explants are shown in the lower panels

with wild-type hair bundles. In particular, slipping artefacts in the mutant would be expected to yield slower activation kinetics, which was not observed. Second, we made sure in wild-type, hypoadapting $U s h 1 c^{\mathrm{dfcr}-2 \mathrm{~J} / \mathrm{dfcr}-2 \mathrm{~J}}$ or hyperadapting Ush $1 c^{\mathrm{dfcr}-2 \mathrm{~J} / \mathrm{dfcr}-2 \mathrm{~J}} \mathrm{OHCs}$ that the extent of adaptation as well as the $I(X)$ curve did not depend on the exact position of the stimulating probe against the hair bundle (Supplementary Fig. 1). In particular, we did not observe a switch between hypoadapting and hyperadapting status in a given cell. Third, we tested whether our stimulation protocol was able to recruit a substantial proportion, if not all, of the stereocilia. We compared transduction currents evoked by a fluid jet, which applies a hydrodynamic force over the whole hair bundle, to those obtained with a stiff glass probe. We used P2-P3 Ush1c ${ }^{-/}$OHCs that lack all harmonin isoforms [32] and have severely damaged hair bundles, thereby performing our control experiments in the worst-case scenario. Currents recorded in $U s h 1 c^{-/-} \mathrm{OHCs}$ at a membrane potential of $-80 \mathrm{mV}$ were much smaller than those measured for Ush $1 c^{+/-}$controls or the wild type [30] but in the same range as those recorded with a stiff fibre (Fig. 6a, b). Incidentally, there was no sign of a resting transduction current at any membrane potential tested in $U s h 1 c^{-/}$OHCs (Fig. 6a). The latter observation was confirmed by the lack of FM1-43 (a styryl dye that permeates transduction channels [18]) loading in the absence of mechanical stimulation of the hair bundle (Fig. 6c). By P7, mechanoelectrical transduction currents in the Ush1c $c^{-/-}$OHCs (Fig. 6b) became almost nonexistent $(20.5 \pm 5 \mathrm{pA}, n=26)$.

\section{Simulation of transduction current recordings}

To interpret our experimental data, we used a minimal physical description of hair bundle mechanics [35, 38]. This description is based on the gating spring theory and a motor model of adaptation (Supplementary Fig. 2). In the corresponding computational model [46], parameter values were constrained by the measured biophysical characteristics of hair bundles (see "Materials and methods"). For wild-type UHCs, the model-based simulations captured the essential features observed on experimental recordings (Fig. 7a). First, for non-saturating displacements, the

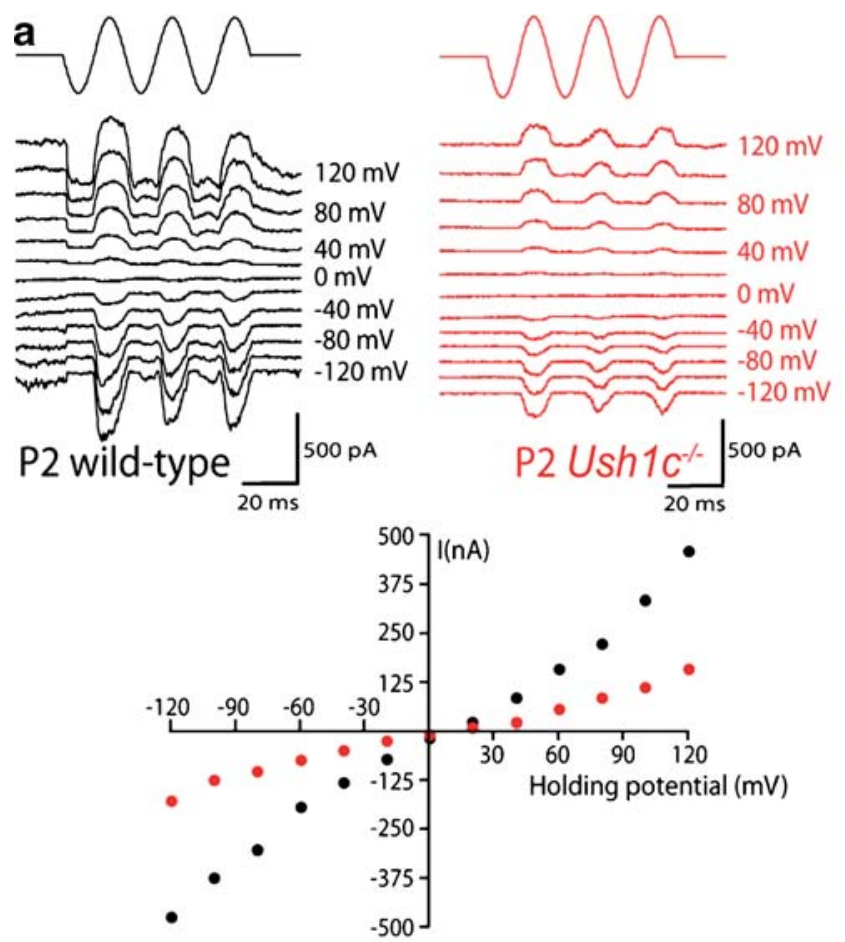

b
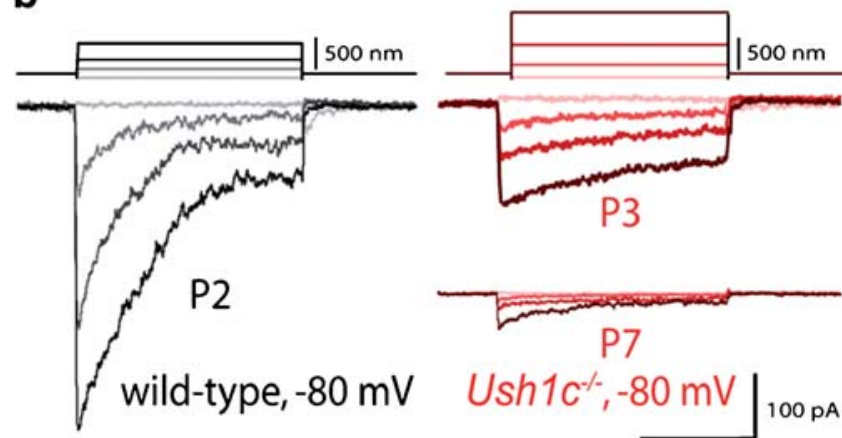

P3
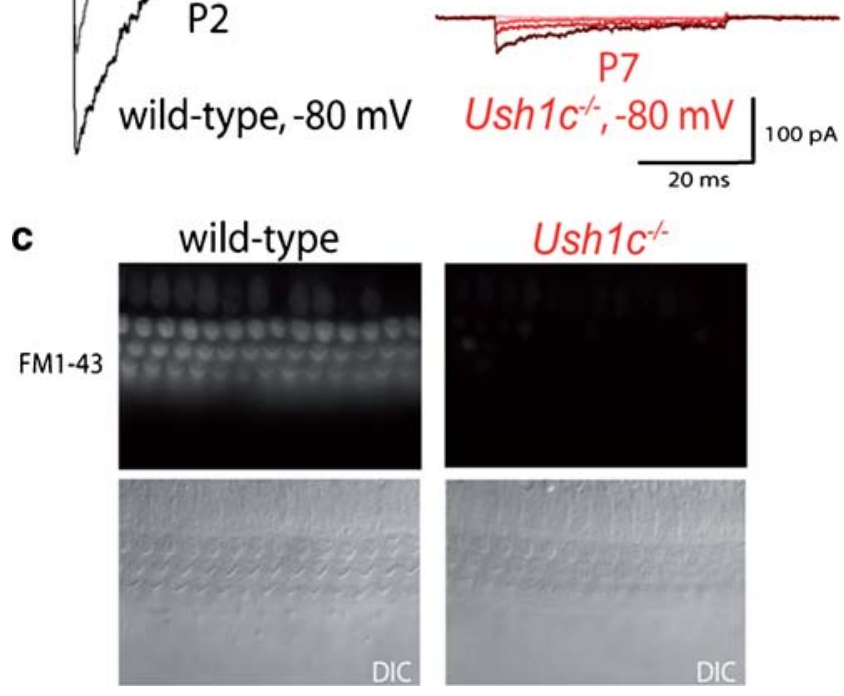

adaptive decrease in transduction current was well fitted by a double exponential relationship. Second, the fast component accounted for about half the extent of adaptation. Third, the extent of adaptation was limited to $\sim 75 \%$, and this did not vary significantly for intermediate open probabilities of the transduction channels. Finally, the model also predicted that saturating displacements would 
result in a sigmoidal time course of current decline during adaptation, and that the extent of adaptation would plummet when the transduction process was almost saturated, as was actually observed in some UHCs (Fig. 2a and data not shown).

Ush1c dfcr-2J/dfcr-2J UHCs offer a unique opportunity to study the role of harmonin-b in mechanoelectrical transduction, for one can exclude the involvement of architectural defects of the hair bundle in shaping the recorded currents. In these cells, the absence of harmonin-b has indeed no effect on the hair bundle morphology, the maximal amplitude of the transduction currents and the $P_{\mathrm{o}}(X)$ curve. Accordingly, we attributed to the parameters controlling these features in the model, namely, $\gamma, N, K_{\mathrm{GS}}$ and $D$ (see "Materials and methods"), identical values to those used in the simulations of wild-type UHC currents. By keeping $K_{\mathrm{SP}}$ and $\lambda$ unchanged, we also ensured that the kinetics of hair bundle movements stayed the same in simulations of wild-type and mutant UHC currents. The extent spring provides the adaptation motors with an elastic load that restricts the extent of adaptation (Supplementary Fig. 2). To account for the hyperadaptive behaviour of Ush $1 c^{\text {dfcr-2J/dfcr-2J }}$ UHCs, we thus decreased the stiffness $\left(K_{\mathrm{ES}}\right)$ of the extent spring. Reducing extent spring stiffness by $20 \%$ increased the proportion of adaptation extent contributed by the fast phase of adaptation, as observed experimentally (Fig. 4). However, it also resulted in a $10 \%$ decrease in adaptation rates (data not shown), whereas adaptation was actually slightly faster in mutant than in wild-type UHCs (Fig. 4). Reducing the number of adaptation motors elicited faster adaptation and did not impinge significantly on the extent of adaptation (data not shown). Altering both the extent spring stiffness and the number of adaptation motors, by $20 \%$ and $40 \%$, respectively, thus afforded a means to reproduce the adaptation features of mutant UHCs (Fig. 7a).

We subsequently used the physical description accounting for mechanoelectrical transduction in UHCs as a basis for discussing the properties of OHCs [46] (Fig. 7b). Parameter values were constrained by the geometry and the stiffness of the hair bundle, and, most importantly, by the rapid kinetics of adaptation (see "Materials and methods"). Consistent with experimental findings, simulations in wildtype OHCs generated an almost mono-exponential adaptive decline of the transduction current (data not shown). In experiments, the effects of harmonin-b absence on OHCs (Fig. 5) were, on average, opposite to those measured in UHCs (Fig. 4). However, they could be described in simulations by applying the same procedure as in UHCs. Reducing the extent spring stiffness and number of adaptation motors by $20 \%$ and $50 \%$, respectively, that is in similar proportions as in the simulations of mutant UHCs, indeed mimicked the adaptation features observed,
Fig. 7 Simulated transduction currents in wild-type and $U s h 1 c^{\mathrm{dfcr}-2 \mathrm{~J} / \mathrm{dfcr}-}$ ${ }^{2 J}$ UHCs and OHCs. a Simulations of transduction currents in UHCs. Top left panel Wild-type UHCs. As in experimental recordings (see "Materials and methods"), each transduction current displays a peak that is followed by an adaptive decline to a plateau. In response to stimuli of small and intermediate magnitudes, the time course of adaptation is well described by a double exponential function. Our minimal model thus produced fast and slow components of adaptation, even though the ratio between fast and slow rates was only 2.5 in the simulation instead of 6 to 8 in the recordings. Intense stimuli produced adaptive currents with a sigmoidal time course that was poorly described by a double exponential (arrowhead). Here and in subsequent figures, the time course of hair bundle position $X$ is shown above the corresponding transduction currents, and the rise time of hair bundle deflections is controlled by $K_{\mathrm{SP}}$ and $\lambda . K_{\mathrm{SP}}=6 \mathrm{pN} \mathrm{nm}^{-1}, K_{\mathrm{GS}}=0.2 \mathrm{pN} \mathrm{nm}^{-1}, K_{\mathrm{ES}}=$ $0.65 \mathrm{pN} \mathrm{nm}^{-1}, D=14 \mathrm{~nm}, N=50, \gamma=0.07, \lambda=0.001 \mathrm{pN} \mathrm{s} \mathrm{nm}^{-1}, \lambda_{\mathrm{a}}=$ $0.015 \mathrm{pN} \mathrm{s} \mathrm{nm}^{-1}, F_{\max }=35 \mathrm{pN}$ and $S=5$. Top middle panel Ush $1 c^{\mathrm{dfcr}-2 \mathrm{~J} /}$ dfcr-2J UHC. Parameter values are the same as those used to describe wild-type UHCs but for $20 \%$ and $40 \%$ decreases in $K_{\mathrm{ES}}$ and the number of adaptation motors, respectively, leading to $K_{\mathrm{ES}}=0.52 \mathrm{pN} \mathrm{nm}^{-1}, \lambda_{\mathrm{a}}=$ $0.009 \mathrm{pN} \mathrm{s} \mathrm{nm}^{-1}$ and $F_{\max }=21 \mathrm{pN}$. Note that decreasing the number of adaptation motors affects by the same proportion both the motor friction $\lambda_{\mathrm{a}}$ and the maximal motor force $F_{\max }$. Top right panel Simulated $P_{\mathrm{o}}(X)$ curves could be fitted with a two-state Boltzmann relation: $I=1 /[1+\exp$ $\left(-\left(X-X_{0}\right) / \delta\right]$, with $\delta=75 \mathrm{~nm}$ and $X_{0}=568.1 \mathrm{~nm}$ for the wild type (black curve) and with $\delta=75 \mathrm{~nm}$ and $X_{0}=641.2 \mathrm{~nm}$ for the Ush1 $c^{\mathrm{dfcr}-2 \mathrm{~J} / \mathrm{dfcr}-2 \mathrm{~J}}$ UHC (blue curve). Lower panels (from left to right) Extent of fast adaptation, contribution of fast adaptation to the adaptation extent ( $\%$ of fast adaptation), fast and slow adaptation rates, all plotted as a function of $P_{\mathrm{o}}$ for the wild-type UHC (black curve) and the Ushlc $c^{\mathrm{dfcr}-2 \mathrm{~J} / \mathrm{dfcr}-2 \mathrm{~J}}$ UHC (blue curve). Note that, in the case where most of the transduction channels are closed at rest, small stimuli elicited slowly adapting responses of little extent. b Simulations of transduction currents in OHCs. Top left panel wild-type OHC. Note that the time scale is different from for simulations of transduction currents in UHCs. $K_{\mathrm{SP}}=3 \mathrm{pN} \mathrm{nm}^{-1}, K_{\mathrm{GS}}=$ $6.5 \mathrm{pN} \mathrm{nm}^{-1}, K_{\mathrm{ES}}=0.75 \mathrm{pN} \mathrm{nm}^{-1}, D=33.1 \mathrm{~nm}, N=150, \gamma=0.25$, $\lambda=0.002 \mathrm{pN} \mathrm{s} \mathrm{nm}^{-1}, \lambda_{\mathrm{a}}=0.001 \mathrm{pN} \mathrm{s} \mathrm{nm}^{-1}, F_{\max }=114 \mathrm{pN}$ and $S=4$. Top middle left and right panels Ush1 $c^{\mathrm{dfcr}-2 \mathrm{~J} / \mathrm{dfcr}-2 \mathrm{~J}} \mathrm{OHC}$. Reducing $N$, and thus all parameters proportional to $N$, by $66 \%$ to account for smaller transduction currents in mutant mice as well as $K_{\mathrm{ES}}$ by $20 \%$ to reproduce the effect of harmonin-b absence unveiled in UHCs produces a hyperadaptive system with slightly faster adaptation (dark blue). In this case, parameters are the same as for the wild-type $\mathrm{OHC}$, except $K_{\mathrm{GS}}=2.17 \mathrm{pN} \mathrm{nm}^{-1}, K_{\mathrm{ES}}=$ $0.2 \mathrm{pN} \mathrm{nm}^{-1}, N=50, \lambda_{\mathrm{a}}=0.333 \mathrm{pN} \mathrm{s} \mathrm{nm}^{-1}$ and $F_{\max }=38 \mathrm{pN}$. An additional reduction of the number of adaptation motors, and thus of $\lambda_{\mathrm{a}}$ and $F_{\max }$, by $50 \%$ instead produces a hypoadaptive behaviour with slower adaptation (light blue). There, $\lambda_{\mathrm{a}}=0.167 \mathrm{pN} \mathrm{s} \mathrm{nm}^{-1}$ and $F_{\max }=19 \mathrm{pN}$. Top right panel Simulated $P_{\mathrm{o}}(X)$ curves plotted for the wild-type OHC (black) and the Ush1 $c^{\mathrm{dfcr}-2 \mathrm{~J} / \mathrm{dfcr}-2 \mathrm{~J}} \mathrm{OHC}$ (blue) could be fitted with a three-state Boltzmann relation: $I=1 /\left[1+\left\{\exp \left(-\left(X-X_{0}\right) / \delta_{0}\right)\right\}\left\{1+\exp \left(-\left(X-X_{1}\right) / \delta_{1}\right)\right\}\right] ?$, with $\delta_{0}=5.3 \mathrm{~nm}, \delta_{1}=11.4 \mathrm{~nm}, X_{0}=172.5 \mathrm{~nm}$ and $X_{1}=266 \mathrm{~nm}$ for wild-type (black), with $\delta_{0}=4.7 \mathrm{~nm}, \delta_{1}=12.5 \mathrm{~nm}, X_{0}=142 \mathrm{~nm}$ and $X_{1}=253.9 \mathrm{~nm}$ for the hyperadaptive case of $U \operatorname{sh} 1 c^{\mathrm{dfcr}-2 \mathrm{~J} / \mathrm{dfcr}-2 \mathrm{~J}}($ dark blue) and with $\delta_{0}=9.5 \mathrm{~nm}, \delta_{1}=9.4 \mathrm{~nm}, X_{0}=248.3 \mathrm{~nm}$ and $X_{1}=$ $439 \mathrm{~nm}$ for the hypoadaptive case of Ush $1 c^{\mathrm{dfcr}-2 \mathrm{~J} / \mathrm{dfcr}-2 \mathrm{~J}}$ (light blue). Lower left panels Extent of adaptation and fast adaptation rate plotted as a function of $P_{\mathrm{o}}$ for the wild-type $\mathrm{OHC}$ (black) and the Ush $1 c^{\mathrm{dfcr}-2 \mathrm{~J} / \mathrm{dfcr}-2 \mathrm{~J}} \mathrm{OHC}$ (blue). Lower right panels extent of adaptation at $P_{\mathrm{o}}=0.5$ as a function of relative variations of $K_{\mathrm{ES}}$ and the number of adaptation motors for simulations of $U \operatorname{sh} 1 c^{\mathrm{dfcr}-2 \mathrm{~J} /}$ dfcr-2J UHCs (dotted line) and OHCs (black line). In each case, the origin corresponds to the parameter set of the corresponding Ush $1 c^{\text {dfcr-2J/dfrr-2J }}$ simulation (light blue) 

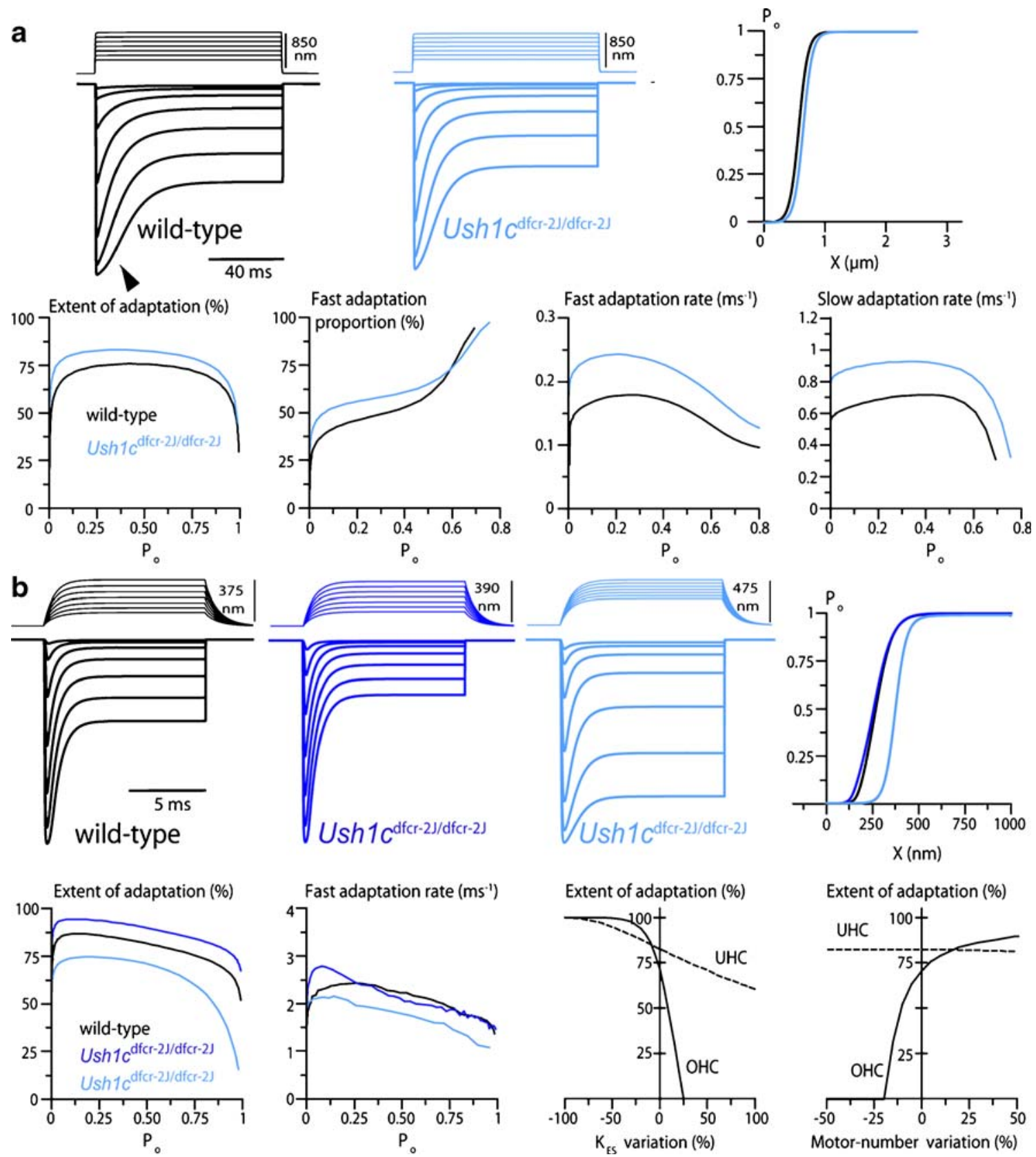

on average, for $U s h 1 c^{\mathrm{dfcr}-2 \mathrm{~J} / \mathrm{dfcr}-2 \mathrm{~J}}$ OHCs (Fig. 7b). In addition, and somewhat unexpectedly, the large variability in the extent of adaptation that was observed in experiments with $U s h 1 c^{\text {dfcr-2J/dfr-2J }}$ OHCs was also obtained in simulations upon moderate changes in either extent spring stiffness or motor number. Notably, these conclusions do not depend on variations of the number $N$ of transduction elements and thus on the value of the maximal transduction current. To account in the simulations for smaller transduction currents in mutant OHCs, we here reduced $N$ and, in turn, all parameters that are proportional to $N$ (namely, $K_{\mathrm{GS}}$, $K_{\mathrm{ES}}, \lambda_{\mathrm{a}}$ and $F_{\max }$ ), by $66 \%$ (Fig. $7 \mathrm{~b}$ ). Under the simplifying

assumption that the total $\mathrm{Ca}^{2+}$ influx per stereocilium, and thus parameter $S$, does not depend on $N$, we qualitatively observed the same behaviour as that shown in Fig. $7 \mathrm{~b}$ when $N$ was kept to the same value as in simulations of currents in wild-type mice (data not shown). However, simulations could not account for the observed positive correlation between the extent of adaptation and the maximal transduction current that $U s h 1 c^{\text {dfcr-2J/dfcr-2J }}$ OHCs produced (Fig. 5d). Decreasing the value of the same two parameters, namely the extent spring stiffness and the number of adaptation motors, was thus sufficient to account for the conflicting behaviours of $U s h 1 c^{\mathrm{dfcr}-2 \mathrm{~J} / \mathrm{dfcr}-2 \mathrm{~J}} \mathrm{UHCs}$ and 
OHCs, including the large variability of adaptation extent that was observed for the latter but not the former.

As is often the case in complex dynamical systems when operating in different regions of the parameter space, the effects of small parameter changes can be contrasted. Reducing extent spring stiffness alone produced hyperadaptive behaviours in simulations of both UHC and OHC currents (Fig. 7b). However, diminishing the number of adaptation motors had the opposite effect for OHCs only and thus afforded a means to produce hypoadaptive behaviours in simulations of OHC currents. Similarly, reducing extent spring stiffness had opposite effects on adaptation kinetics in the two cell types. The same was true for changes in the number of adaptation motors. Finally, a great sensitivity of the extent of adaptation to moderate changes in either extent spring stiffness or the number of adaptation motors was observed in simulations of $\mathrm{OHC}$ currents but not UHC currents (Fig. 7b).

\section{Discussion}

Electrophysiological recordings revealed that adaptation of mechanoelectrical transducer currents in response to hair bundle stimulation was abnormal in harmonin-b-deficient $\left(U_{s h} 1 c^{\mathrm{dffr}-2 \mathrm{~J} / \mathrm{dfcr}-2 \mathrm{~J}}\right) \mathrm{UHCs}$ and OHCs. The increased extent and faster kinetics of adaptation in $U s h 1 c^{\mathrm{dfcr}-2 \mathrm{~J} / \mathrm{dfr}-2 \mathrm{~J}} \mathrm{UHCs}$ shows that harmonin-b is involved in this process. In these cells, the absence of harmonin-b has indeed no detectable effects on hair bundle architecture, on the magnitude of the transduction currents and on the current-displacement relationship of the hair bundle. Simulations based on a theoretical description of mechanoelectrical transduction $[35,38,41,46]$ accounted for the essential features of our electrophysiological data by attributing the effects of the absence of harmonin-b to alterations in the adaptation machinery. Reducing the stiffness of the extent spring was a modification expected to account for the hyperadaptive behaviour of Ush $1 c^{\mathrm{dfcr}-2 \mathrm{~J} / \mathrm{dfcr}-2 \mathrm{~J}}$ UHCs. However, this change could not, by itself, explain the higher slow adaptation rate observed in these cells, thus arguing in favour of an additional role of harmonin-b. Adaptation kinetics can be controlled by altering the number of molecular motors that contribute to adaptation. Reducing concurrently the extent spring stiffness and the number of adaptation motors could account for the adaptation features of Ush $1 c^{\mathrm{dfcr}-2 \mathrm{~J} / \mathrm{dfcr}-2 \mathrm{~J}} \mathrm{UHCs}$. In Ush $1 c^{\mathrm{dfcr}-2 \mathrm{~J} / \mathrm{dfcr}-2 \mathrm{~J}} \mathrm{OHCs}$, mild architectural defects were probably responsible for the reduced transduction currents and sensitivity of the $P_{\mathrm{o}}(X)$ relation, as well as for a bias of the adaptation extent towards the hypoadaptive behaviour. Mutant hair cells with large transduction currents $\left(I_{\max }>450 \mathrm{pA}\right)$ indeed displayed a $P_{\mathrm{o}}(X)$ relation that was normal and were only slightly hypoadaptative on average. However, slower adaptation kinetics and a large variability of adaptation extent were observed irrespective of the transduction current magnitude and thus of the structural damage that the cells may have undergone. Quite unexpectedly, these effects, which were observed in mutant OHCs but not in mutant UHCs, could be described by the same simulation procedure that could account for the behaviour of $U s h 1 c^{\mathrm{dfcr}-2 \mathrm{~J} / \mathrm{dfcr}-2 \mathrm{~J}} \mathrm{UHCs}$.

How is it that similar parameter changes in the simulations produced opposite effects? Fast adaptation kinetics is the essential feature that distinguishes transduction in wild-type OHCs and UHCs. Adaptation in OHCs is so fast that the transduction current peaks well before the stimulus probe has settled to a steady-state position. Adaptation in these cells thus proceeds, while their hair bundle is still moving forward, a feature that was not observed in UHCs (see "Materials and methods"). Only when simulations mimicked this experimental constraint (Fig. 7b) could we reproduce the effects of harmonin absence in OHCs. The differences observed between UHCs and OHCs may therefore be attributable to the too brisk adaptation kinetics in OHCs as compared with the fastest hair bundle deflections afforded by our piezoelectric actuator. With ultrafast stimulation but otherwise identical parameters as those used in Fig. 7b, simulations indeed restored an adaptive behaviour similar to that of UHCs, though more rapid (data not shown). We thus predict that adaptation in mutant OHCs should in fact behave as in mutant UHCs, just faster. This prediction ought to be confirmed once fast stimulation techniques become available. In addition, our results may shed light on a recent study of mechanoelectrical transduction in mutant mice that do not express any of the three classes of harmonin isoforms but only a rearranged form comprised of the three PDZ domains [20]. In these mice, adaptation in OHCs was slower than in wild-type mice, an observation similar to ours, and the resting open probability was reduced. To account for the latter observation, the authors proposed that harmonin recruits adaptation motors. However, they could not explain how a reduction of the number of motor molecules in mutant mice would result in slower adaptation. Our modelling work indicates that a reduced number of adaptation motors can indeed, under conditions of relatively slow stimulation, result in a reduced speed of adaptation.

Our results suggest that harmonin-b contributes to the extent spring and the recruitment of adaptation motors in the region of the tip link's upper insertion point. This dual role is consistent with the known biochemical properties of the protein. Harmonin-b can bind in vitro to the cytoplasmic region of cadherin-23 [10, 42], a protein whose extracellular domain has been shown to make up the upper part of the tip link [2, 26, 43]. Supporting the in vivo 
relevance of this interaction, harmonin-b is initially present at the stereociliary tip in mouse mutants defective for cadherin- 23 but is not subsequently detected in the region of the upper insertion point of the tip link as in wild-type mice [32]. Harmonin-b also binds to actin filaments [10] and therefore is qualified to connect the tip link to the stereociliary cytoskeleton. If molecular motors are able to pull on the upper end of the tip link, harmonin-b is thus expected to limit the extent of their movements. Resting tension in the tip link is required for the transduction apparatus to operate within a sensitive range of hair bundle deflections [24]. Insofar as plus-end directed myosin motors are the only available candidates to produce this tension, motor molecules are indeed likely to work in the vicinity of harmonin-b. Such motors are expected to mediate adaptation by moving along the actin core of the stereocilia in response to external stimuli. The role of harmonin-b in engaging adaptation motors to the mechanoelectrical transduction apparatus could involve direct or indirect interaction of harmonin-b with myosin-VIIa and myosin-1c that have been reported to operate as adaptation motors in the hair bundle. A chemical-genetic strategy in the mouse has indeed provided strong support to a critical role of myosin-1c in the adaptation process of vestibular hair cells [21, 45]. Moreover, the cross-bridge cycle of myosin-1c has been shown to be regulated by calcium, resulting in an acceleration of detachment of the crossbridge and a lengthening of the lifetime of the myosin detached state at increased $\mathrm{Ca}^{2+}$ concentrations [1]. This property accords with the posited existence of electromechanical feedback by the $\mathrm{Ca}^{2+}$ component of the transduction current on the activity of adaptation motors. On the other hand, increases in the rate of slipping adaptation and a loss of climbing adaptation have been reported for cochlear hair cells from mutant mice carrying a null mutation in the myosin-VIIa gene [29]. Harmonin-b, which acts as a scaffolding protein via its three PDZ domains, indeed directly interacts with the myosin-VIIa tail in vitro [10]. Substantiating the in vivo interaction between these two proteins, harmonin-b is not properly targeted to the hair bundle in myosin-VIIa-deficient mice, and reciprocally, myosin-VIIa does not concentrate at the stereocilia tip in harmonin-deficient mice [10, 32]. Moreover, the binding of cadherin-23 to harmonin-b might influence the interaction of myosin-1c with the cytoplasmic region of cadherin-23 [43]. Finally, the recent observation that the exertion of a force of only a few piconewtons on myosin-I is sufficient to lock this motor protein to actin [31] raises the possibility that the extent spring also includes myosin molecules. An abrupt positive deflection of the hair bundle might block those motor molecules attached at the onset of stimulation while other motor molecules are mediating the adaptive process. In this case, the absence of harmonin-b would be expected to alter, concomitantly, the number of molecular motors involved in the extent spring and adaptation kinetics.

Acknowledgements We thank Jacqueline Levilliers for her help in the preparation of the manuscript and Jacques Boutet de Monvel for critical reading of the manuscript. N.M. was supported by a fellowship from the Fondation pour la Recherche Médicale and the Ministère de l'Education Nationale, de la Recherche et de la Technologie. This work was supported by the Fondation Raymonde et Guy Strittmatter, the European Commission FP6 Integrated Project EuroHear LSHGCT-2004-512063, Ernst-Jung Stiftung für Medizin Preis, FAUN Stiftung (Suchert Foundation) and the Ministère de la RechercheACI Interface Physique-Chimie-Biologie-DRAB02/102.

Open Access This article is distributed under the terms of the Creative Commons Attribution Noncommercial License which permits any noncommercial use, distribution, and reproduction in any medium, provided the original author(s) and source are credited.

\section{References}

1. Adamek N, Coluccio LM, Geeves MA (2008) Calcium sensitivity of the cross-bridge cycle of Myolc, the adaptation motor in the inner ear. Proc Natl Acad Sci U S A 105:5710-5715

2. Ahmed ZM, Goodyear R, Riazuddin S, Lagziel A, Legan PK, Behra M, Burgess SM, Lilley KS, Wilcox ER, Riazuddin S, Griffith AJ, Frolenkov GI, Belyantseva IA, Richardson GP, Friedman TB (2006) The tip-link antigen, a protein associated with the transduction complex of sensory hair cells, is protocadherin-15. J Neurosci 26:7022-7034

3. Assad JA, Corey DP (1992) An active motor model for adaptation by vertebrate hair cells. J Neurosci 12:3291-3309

4. Assad JA, Hacohen N, Corey DP (1989) Voltage dependence of adaptation and active bundle movement in bullfrog saccular hair cells. Proc Natl Acad Sci U S A 86:2918-2922

5. Assad JA, Shepherd GM, Corey DP (1991) Tip-link integrity and mechanical transduction in vertebrate hair cells. Neuron 7:985-994

6. Beurg M, Evans MG, Hackney CM, Fettiplace R (2006) A largeconductance calcium-selective mechanotransducer channel in mammalian cochlear hair cells. J Neurosci 26:10992-11000

7. Beurg M, Fettiplace R, Nam JH, Ricci AJ (2009) Localization of inner hair cell mechanotransducer channels using high-speed calcium imaging. Nat Neurosci 12:553-558

8. Beurg M, Nam JH, Crawford A, Fettiplace R (2008) The actions of calcium on hair bundle mechanics in mammalian cochlear hair cells. Biophys J 94:2639-2653

9. Bitner-Glindzicz M, Lindley KJ, Rutland P, Blaydon D, Smith VV, Milla PJ, Hussain K, Furth-Lavi J, Cosgrove KE, Shepherd RM, Barnes PD, O'Brien RE, Farndon PA, Sowden J, Liu XZ, Scanlan MJ, Malcolm S, Dunne MJ, Aynsley-Green A, Glaser B (2000) A recessive contiguous gene deletion causing infantile hyperinsulinism, enteropathy and deafness identifies the Usher type 1C gene. Nat Genet 26:56-60

10. Boëda B, El-Amraoui A, Bahloul A, Goodyear R, Daviet L, Blanchard S, Perfettini I, Fath KR, Shorte S, Reiners J, Houdusse A, Legrain P, Wolfrum U, Richardson G, Petit C (2002) Myosin VIIa, harmonin, and cadherin 23 , three Usher I gene products, cooperate to shape the sensory hair cell bundle. EMBO J 21:6689-6699

11. Cheung EL, Corey DP (2006) Ca2+ changes the force sensitivity of the hair-cell transduction channel. Biophys J 90:124-139

12. Choe Y, Magnasco MO, Hudspeth AJ (1998) A model for amplification of hair-bundle motion by cyclical binding of $\mathrm{Ca} 2+$ 
to mechanoelectrical-transduction channels. Proc Natl Acad Sci U S A 95:15321-15326

13. Corey DP, Hudspeth AJ (1983) Kinetics of the receptor current in bullfrog saccular hair cells. J Neurosci 3:962-976

14. Crawford AC, Evans MG, Fettiplace R (1989) Activation and adaptation of transducer currents in turtle hair cells. J Physiol 419:405-434

15. Crawford AC, Evans MG, Fettiplace R (1991) The actions of calcium on the mechano-electrical transducer current of turtle hair cells. J Physiol 434:369-398

16. Eatock RA (2000) Adaptation in hair cells. Annu Rev Neurosci 23:285-314

17. Eatock RA, Corey DP, Hudspeth AJ (1987) Adaptation of mechanoelectrical transduction in hair cells of the bullfrog's sacculus. J Neurosci 7:2821-2836

18. Gale JE, Marcotti W, Kennedy HJ, Kros CJ, Richardson GP (2001) FM1-43 dye behaves as a permeant blocker of the hair-cell mechanotransducer channel. J Neurosci 21:7013-7025

19. Geleoc GS, Holt JR (2003) Developmental acquisition of sensory transduction in hair cells of the mouse inner ear. Nat Neurosci 6:1019-1020

20. Grillet N, Xiong W, Reynolds A, Kazmierczak P, Sato T, Lillo C, Dumont RA, Hintermann E, Sczaniecka A, Schwander M, Williams D, Kachar B, Gillespie PG, Muller U (2009) Harmonin mutations cause mechanotransduction defects in cochlear hair cells. Neuron 62:375-387

21. Holt JR, Gillespie SK, Provance DW, Shah K, Shokat KM, Corey DP, Mercer JA, Gillespie PG (2002) A chemical-genetic strategy implicates myosin-1c in adaptation by hair cells. Cell 108:371381

22. Howard J, Hudspeth AJ (1987) Mechanical relaxation of the hair bundle mediates adaptation in mechanoelectrical transduction by the bullfrog's saccular hair cell. Proc Natl Acad Sci U S A 84:3064-3068

23. Hudspeth AJ (2008) Making an effort to listen: mechanical amplification in the ear. Neuron 59:530-545

24. Hudspeth AJ, Gillespie PG (1994) Pulling springs to tune transduction: adaptation by hair cells. Neuron 12:1-9

25. Johnson KR, Gagnon LH, Webb LS, Peters LL, Hawes NL, Chang B, Zheng QY (2003) Mouse models of USH1C and DFNB18: phenotypic and molecular analyses of two new spontaneous mutations of the Ush1c gene. Hum Mol Genet 12:3075-3086

26. Kazmierczak P, Sakaguchi H, Tokita J, Wilson-Kubalek EM, Milligan RA, Muller U, Kachar B (2007) Cadherin 23 and protocadherin 15 interact to form tip-link filaments in sensory hair cells. Nature 449:87-91

27. Kennedy HJ, Evans MG, Crawford AC, Fettiplace R (2003) Fast adaptation of mechanoelectrical transducer channels in mammalian cochlear hair cells. Nat Neurosci 6:832-836

28. Kozlov AS, Risler T, Hudspeth AJ (2007) Coherent motion of stereocilia assures the concerted gating of hair-cell transduction channels. Nat Neurosci 10:87-92

29. Kros CJ, Marcotti W, van Netten SM, Self TJ, Libby RT, Brown SD, Richardson GP, Steel KP (2002) Reduced climbing and increased slipping adaptation in cochlear hair cells of mice with Myo7a mutations. Nat Neurosci 5:41-47

30. Kros CJ, Rusch A, Richardson GP (1992) Mechano-electrical transducer currents in hair cells of the cultured neonatal mouse cochlea. Proc Biol Sci 249:185-193

31. Laakso JM, Lewis JH, Shuman H, Ostap EM (2008) Myosin I can act as a molecular force sensor. Science 321:133-136

32. Lefevre G, Michel V, Weil D, Lepelletier L, Bizard E, Wolfrum U, Hardelin J-P, Petit C (2008) A core cochlear phenotype in USH1 mouse mutants implicates fibrous links of the hair bundle in its cohesion, orientation and differential growth. Development 135:1427-1437

33. Lelli A, Asai Y, Forge A, Holt JR, Geleoc GS (2009) Tonotopic gradient in the developmental acquisition of sensory transduction in outer hair cells of the mouse cochlea. J Neurophysiol 101:2961-2973

34. Martin P (2008) Active hair-bundle motility of the hair cells of vestibular and auditory organs. In: Manley GA, Popper AN, Fay RR (eds) Active processes and otoacoustic emissions. Springer, New York

35. Martin P, Bozovic D, Choe Y, Hudspeth AJ (2003) Spontaneous oscillation by hair bundles of the bullfrog's sacculus. J Neurosci 23:4533-4548

36. Michalski N, Michel V, Bahloul A, Lefevre G, Barral J, Yagi H, Chardenoux S, Weil D, Martin P, Hardelin JP, Sato M, Petit C (2007) Molecular characterization of the ankle-link complex in cochlear hair cells and its role in the hair bundle functioning. J Neurosci 27:6478-6488

37. Michel V, Goodyear RJ, Weil D, Marcotti W, Perfettini I, Wolfrum U, Kros C, Richardson GP, Petit C (2005) Cadherin 23 is a component of the transient lateral links in the developing hair bundles of cochlear sensory cells. Dev Biol 280:281-294

38. Nadrowski B, Martin P, Julicher F (2004) Active hair-bundle motility harnesses noise to operate near an optimum of mechanosensitivity. Proc Natl Acad Sci U S A 101:12195-12200

39. Pickles JO, Comis SD, Osborne MP (1984) Cross-links between stereocilia in the guinea pig organ of Corti, and their possible relation to sensory transduction. Hear Res 15:103-112

40. Ricci AJ, Crawford AC, Fettiplace R (2002) Mechanisms of active hair bundle motion in auditory hair cells. J Neurosci 22:44 52

41. Shepherd GM, Corey DP (1994) The extent of adaptation in bullfrog saccular hair cells. J Neurosci 14:6217-6229

42. Siemens J, Kazmierczak P, Reynolds A, Sticker M, LittlewoodEvans A, Muller U (2002) The Usher syndrome proteins cadherin 23 and harmonin form a complex by means of PDZ-domain interactions. Proc Natl Acad Sci USA 99:14946-14951

43. Siemens J, Lillo C, Dumont RA, Reynolds A, Williams DS, Gillespie PG, Muller U (2004) Cadherin 23 is a component of the tip link in hair-cell stereocilia. Nature 428:950-955

44. Stauffer EA, Holt JR (2007) Sensory transduction and adaptation in inner and outer hair cells of the mouse auditory system. J Neurophysiol 98:3360-3369

45. Stauffer EA, Scarborough JD, Hirono M, Miller ED, Shah K, Mercer JA, Holt JR, Gillespie PG (2005) Fast adaptation in vestibular hair cells requires myosin-1c activity. Neuron 47:541-553

46. Tinevez JY, Julicher F, Martin P (2007) Unifying the various incarnations of active hair-bundle motility by the vertebrate hair cell. Biophys J 93:4053-4067

47. van Aken AF, Atiba-Davies M, Marcotti W, Goodyear RJ, Bryant JE, Richardson GP, Noben-Trauth K, Kros CJ (2008) TRPML3 mutations cause impaired mechano-electrical transduction and depolarization by an inward-rectifier cation current in auditory hair cells of varitint-waddler mice. J Physiol 586:5403-5418

48. Verpy E, Leibovici M, Zwaenepoel I, Liu XZ, Gal A, Salem N, Mansour A, Blanchard S, Kobayashi I, Keats BJ, Slim R, Petit C (2000) A defect in harmonin, a PDZ domain-containing protein expressed in the inner ear sensory hair cells, underlies Usher syndrome type 1C. Nat Genet 26:51-55

49. Waguespack J, Salles FT, Kachar B, Ricci AJ (2007) Stepwise morphological and functional maturation of mechanotransduction in rat outer hair cells. J Neurosci 27:13890-13902

50. Wu YC, Ricci AJ, Fettiplace R (1999) Two components of transducer adaptation in auditory hair cells. J Neurophysiol $82: 2171-2181$ 